\title{
Deciphering the potential involvement of PXMP2 and PEX11B in hydrogen peroxide permeation across the peroxisomal membrane reveals a role for PEX11B in protein sorting
}

Celien Lismont ${ }^{1}$, Janet Koster ${ }^{2}$, Sarah Provost ${ }^{1}$, Myriam Baes ${ }^{3}$, Paul P. Van Veldhoven', Hans R. Waterham², Marc Fransen,",

${ }^{1}$ Laboratory of Lipid Biochemistry and Protein Interactions, Department of Cellular and Molecular Medicine, KU Leuven - University of Leuven, Herestraat 49 box 601, B-3000 Leuven, Belgium

${ }^{2}$ Laboratory Genetic Metabolic Diseases, Amsterdam UMC, Academic Medical Center, University of Amsterdam, Meibergdreef 9, 1105 AZ Amsterdam, the Netherlands

${ }^{3}$ Laboratory of Cell Metabolism, Department of Pharmaceutical and Pharmacological Sciences, KU Leuven - University of Leuven, Herestraat 49 box 823, B-3000 Leuven, Belgium

* Corresponding author: Prof. Dr. Marc Fransen (phone: +32 16 330114; email address: marc.fransen@kuleuven.be)

Running head: Potential involvement of PXMP2 and PEX11B in $\mathrm{H}_{2} \mathrm{O}_{2}$ permeation 


\section{Highlights}

- Co-inactivation of PXMP2 and PEX11B decreases the intraperoxisomal GSSG/GSH ratio.

- $\mathrm{H}_{2} \mathrm{O}_{2}$ efficiently permeates the peroxisomal membrane in $\triangle \mathrm{PXMP} 2 \Delta \mathrm{PEX} 11 \mathrm{~B} H E K-$ 293 cells.

- Loss of PEX11B decreases peroxisome density in HEK-293 cells

- Loss of PEX11B causes partial localization of peroxisomal proteins to mitochondria.

- Mitochondrial po-roGFP2 is exposed to an oxidizing environment in $\triangle \mathrm{PEX} 11 \mathrm{~B}$ cells. 


\begin{abstract}
Peroxisomes have the intrinsic ability to produce and scavenge hydrogen peroxide $\left(\mathrm{H}_{2} \mathrm{O}_{2}\right)$, a diffusible second messenger that controls diverse cellular processes by modulating protein activity through cysteine oxidation. Current evidence indicates that $\mathrm{H}_{2} \mathrm{O}_{2}$, a molecule whose physicochemical properties are similar to those of water, traverses cellular membranes through specific aquaporin channels, called peroxiporins. Until now, no peroxiporin-like proteins have been identified in the peroxisomal membrane, and it is widely assumed that small molecules such as $\mathrm{H}_{2} \mathrm{O}_{2}$ can freely permeate this membrane through PXMP2, a non-selective pore-forming protein with an upper molecular size limit of 300-600 Da. By employing the CRISPR-Cas9 technology in combination with a Flp-In T-REx 293 cell line that can be used to selectively generate $\mathrm{H}_{2} \mathrm{O}_{2}$ inside peroxisomes in a controlled manner, we provide evidence that PXMP2 is not essential for $\mathrm{H}_{2} \mathrm{O}_{2}$ permeation across the peroxisomal membrane, neither in control cells nor in cells lacking PEX11B, a peroxisomal membrane-shaping protein whose yeast homologue facilitates the permeation of molecules up to $400 \mathrm{Da}$. During the course of this study, we unexpectedly noted that inactivation of PEX11B leads to partial localization of both peroxisomal membrane and matrix proteins to mitochondria and a decrease in peroxisome density. These findings are discussed in terms of the formation of a functional peroxisomal matrix protein import machinery in the outer mitochondrial membrane.
\end{abstract}

\title{
Keywords
}

Peroxisomes; hydrogen peroxide; membrane permeation; redox signaling; protein targeting; mitochondria. 


\section{Introduction}

Peroxisomes are membrane-enclosed organelles that serve a central role in diverse metabolic processes. In mammals, these include the $\alpha$ - and $\beta$-oxidation of fatty acids, the biosynthesis of ether-phospholipids, the detoxification of glyoxylate, the oxidation of polyamines, and the catabolism of amino acids [1,2]. Many of the enzymes involved in these pathways produce hydrogen peroxide $\left(\mathrm{H}_{2} \mathrm{O}_{2}\right)$ as part of their catalytic cycle [3]. To counteract the potential harmful effects of $\mathrm{H}_{2} \mathrm{O}_{2}$, peroxisomes are equipped with various antioxidant defense mechanisms, of which catalase $(\mathrm{CAT})^{1}$ and peroxiredoxin 5 (PRDX5) are central components [4].

Non-radical reactive oxygen species (ROS) such as $\mathrm{H}_{2} \mathrm{O}_{2}$ may not only function as mediators of oxidative injury, but also act as second messengers that modulate protein activity through cysteine oxidation, a phenomenon that controls almost all aspects of life [5]. Given that peroxisomes have the intrinsic ability to produce and scavenge $\mathrm{H}_{2} \mathrm{O}_{2}$, these organelles have the potential to modulate $\mathrm{H}_{2} \mathrm{O}_{2}$-mediated signaling pathways [6]. In line with this idea, it has been demonstrated that alterations in mammalian peroxisomal $\mathrm{H}_{2} \mathrm{O}_{2}$ metabolism can have profound effects on nuclear gene expression [7-9], energy metabolism [10], autophagy [11], inflammation [8,12], cell proliferation [13-16], cell senescence [17], cell survival [18-21], and the consumption of extracellular $\mathrm{H}_{2} \mathrm{O}_{2}$ [22]. Importantly, although the exact molecular events underlying these phenomena remain to be elucidated, these and related observations underscore the view that $\mathrm{H}_{2} \mathrm{O}_{2}$ can efficiently permeate the peroxisomal membrane [4].

Currently, there is ample evidence that (i) the permanent dipole moment of $\mathrm{H}_{2} \mathrm{O}_{2}$ is higher than that of water [23], (ii) native biological membranes, including the peroxisomal membrane, serve as significant permeability barriers for $\mathrm{H}_{2} \mathrm{O}_{2}$ [24,25], and (iii) efficient $\mathrm{H}_{2} \mathrm{O}_{2}$ permeation across such membranes requires specialized channels, referred to as "peroxiporins" $[5,26]$. Surprisingly, despite strong evidence that peroxisomes may serve as guardians and modulators of cellular $\mathrm{H}_{2} \mathrm{O}_{2}$ levels [6], no peroxiporin-like proteins have yet been identified in

\footnotetext{
${ }^{1}$ List of non-standard abbreviations: c, cytosolic; CAT, catalase; DAO, D-amino acid oxidase; DD, destabilization domain; DKO, double knockout; DOX, doxycycline; GSH, reduced glutathione; GSSG, oxidized glutathione; HEK, human embryonic kidney; IMS, mitochondrial intermembrane space; mt, mitochondrial; PAM, protospacer adjacent motif; PEX, peroxin (protein involved in peroxisome biogenesis); PMP, peroxisomal membrane protein; po, peroxisomal; ROS, reactive oxygen species; PRDX, peroxiredoxin; PTS, peroxisomal targeting signal; TOMM, translocase of outer mitochondrial membrane; TUBA, tubulin alpha.
} 
the peroxisomal membrane. In general, it is assumed that small molecules such as $\mathrm{H}_{2} \mathrm{O}_{2}$ freely penetrate the peroxisomal membrane through non-selective pore-forming proteins, the most likely candidates being PXMP2 and members of the peroxin 11 (PEX11) protein family [27]: PXMP2 is a widely-expressed and abundant homotrimeric peroxisomal membrane protein (PMP) that displays channel-forming activity and allows free diffusion of compounds with an upper molecular size limit of 300-600 Da [28]; and PEX11A, PEX11B, and PEX11G (the mammalian isoforms of PEX11) are peroxisomal membrane-shaping proteins [29-31] whose yeast homologue facilitates the permeation of molecules up to $400 \mathrm{Da}[32,33]$. Until now, no human disorders have been associated with PXMP2, and targeted disruption of the PXMP2 gene in mice did not cause severe peroxisomal derangements or systemic illness, at least in males [34]. In female mice, phenotypic analysis revealed changes in the lipid composition of the mammary fat pad and defective mammary epithelial growth, a phenomenon that could not be counteracted by feeding a dietary antioxidant diet [34]. The relative mild phenotype may be attributable to the presence of other peroxisomal channel-forming proteins with partially redundant activities [35-39]. Among the mammalian members of the PEX11 protein family, only mutations in $P E X 11 A$, a gene predominantly expressed in adipose tissue, liver, kidney, heart, gastrocnemius, and brain [40], and PEX11B, a widely expressed gene [41], have currently been linked to disease. Indeed, in mice, a deficiency of PEX11A or PEX11B causes, respectively, dyslipidemia and obesity [40] or a severe Zellweger syndrome-like phenotype [42]; and in humans, defective PEX11B results in a Zellweger spectrum disorder with a relatively mild clinical phenotype (e.g., congenital cataract, progressive hearing loss, polyneuropathy, gastrointestinal problems, and mild intellectual disability) [43,44]. However, unlike in other peroxisome biogenesis disorders, mutations in PEX11B (i) do not (e.g., in mouse hepatocytes) or only mildly (e.g., in human skin fibroblasts) affect peroxisomal protein import, and (ii) do not (e.g., in human erythrocytes and cultured skin fibroblasts) or only mildly (e.g., in human plasma and mouse liver and brain) alter biochemical parameters used to diagnose peroxisomal deficiencies [42-44]. Interestingly, deletion of a single allele of the PEX11B gene in mice is apparently sufficient to cause oxidative stress in primary neuronal cultures from the neocortex [45].

In the present study, we provide evidence that PXMP2 and PEX11B, the predominant isoform of PEX11 [46], are not essential for $\mathrm{H}_{2} \mathrm{O}_{2}$ permeation across the peroxisomal membrane in human embryonic kidney (HEK)-293 cells. In addition, we demonstrate that inactivation of PEX11B in HEK-293 cells as well as in HepG2 human hepatocellular carcinoma cells leads to 
partial localization of peroxisomal membrane proteins to mitochondria and the assembly of a functional peroxisomal matrix protein import machinery in the outer mitochondrial membrane. The potential implications of these findings are discussed.

\section{Materials and Methods}

\subsection{Cell culture, electroporations, and fluorescence microscopy}

The DD-myc-DAO Flp-In T-REx 293 cell line has been described elsewhere [4]. The human HepG2 hepatocellular carcinoma cell line was purchased from the American Type Culture Collection (ATCC, HB-8065). All cells were cultured at $37^{\circ} \mathrm{C}$ in a humidified $5 \% \mathrm{CO}_{2}$ incubator in $\alpha$-modified minimum essential medium Eagle (MEM $\alpha$; Lonza, BE12-169F) supplemented with 10\% (v/v) fetal bovine serum (Biowest, S181B), $2 \mathrm{mM}$ ultraglutamine-1 (Lonza, BE17-605E/U1), and 0.2\% (v/v) Mycozap (Lonza, VZA-2012). Culture dishes for HepG2 cells were routinely precoated with collagen type I (BD Biosciences, 354236) at 10 $\mu \mathrm{g} / \mathrm{cm}^{2}$ in $0.02 \mathrm{~N}$ acetic acid (overnight, $37^{\circ} \mathrm{C}$ ).

DD-myc-DAO Flp-In T-REx 293 (electroporation parameters: $1150 \mathrm{~V}, 20$-ms pulse width, 2 pulses) and HepG2 (electroporation parameters: $1200 \mathrm{~V}, 50$-ms pulse width, 1 pulse) cells were transfected with plasmid DNA by using the Neon Transfection System (Thermo Fischer Scientific) in combination with a home-made sucrose-based buffer ( $250 \mathrm{mM}$ sucrose and $1 \mathrm{mM} \mathrm{MgCl} 2$ in Dulbecco's phosphate-buffered saline (Gibco, 14190)) [47]. To induce expression of DD-myc-DAO in Flp-In T-REx 293 cells, doxycycline (DOX) $(1 \mu \mathrm{g} / \mathrm{ml}$; Sigma, D9891) and Shield1 (500 nM; Clontech, 632189) were added to the cell culture medium for 2 or 3 days, as specified in the figure legends. Next, the cells were chased for one day in regular medium without DOX/Shield1. When applicable, cells were incubated with $200 \mathrm{nM}$ of Mitotracker $^{\mathrm{TM}}$ Red CM-H $\mathrm{H}_{2}$ XRos (Thermo Fischer Scientific, M7513) and $5 \mu \mathrm{g} / \mathrm{ml}$ Hoechst 33258 (Sigma, 14530) in regular MEM $\alpha$ medium for 30 minutes.

Samples for immunofluorescence microscopy were fixed, counterstained with $0.5 \mu \mathrm{g} / \mathrm{ml}$ DAPI (Sigma, D-9542) in PBS for 1 minute, and processed as described before [48]. Cells for live-cell imaging were seeded and imaged in FluoroDish cell culture dishes (World Precision Instruments, FD35). To enhance the adherence of the Flp-In T-REx 293 cells to the glass surface, the dishes were precoated with polyethyleneimine with a molecular mass range between 50 and $100 \mathrm{kDa}$ (MP Biomedicals, 195444) at $25 \mu \mathrm{g} / \mathrm{ml}$ in $150 \mathrm{mM} \mathrm{NaCl} \mathrm{(2} \mathrm{h,} \mathrm{room}$ temperature) [49]. Fluorescence was evaluated on a motorized inverted IX-81 microscope 
(Olympus), controlled by $\mathrm{Cell}^{\wedge} \mathrm{M} / \mathrm{xcellence}$ software (Olympus) and equipped with a temperature-, humidity-, and $\mathrm{CO}_{2}$-controlled incubation chamber. The technical specifications of the objectives, excitation and emission filters, and digital camera have been described elsewhere [50]. Ratiometric redox measurements using roGFP2-based probes were performed as described [51]. Briefly, random fields of cells were imaged with the same 400/480 nm exposure time ratios, and images having signal intensities within the linear dynamic range of the CCD camera were retained for analysis. In cells with a dual peroxisomal-mitochondrial staining pattern of po-roGFP2, the oxidation state of the redox sensor in each location was measured in regions that, based on morphology and signal intensity, could be unambiguously identified as peroxisomes or mitochondria. The $\mathrm{Cell}^{\wedge} \mathrm{M} / \mathrm{xcellence}$ software was used to quantify the relative fluorescence intensities of roGFP2 (recorded around $510 \mathrm{~nm}$ ) at $400 \mathrm{~nm}$ and 480 $\mathrm{nm}$ excitation. For the background subtraction, regions-of-interest were selected on neighboring cell-free areas. Anti-GFP nanobody-based plasma membrane translocation assays to study protein-protein interactions in Flp-In T-REx 293 cells were performed as described elsewhere $[52]$.

\subsection{Generation of gene knockout cells by CRISPR-Cas9 genome editing}

The CRISPR-Cas9 genome editing technology as described by Zhang and co-workers [53] was used to introduce functional disruptions of the PXMP2 and/or PEX11B genes in DDmyc-DAO Flp-In T-REx 293 cells [4] and/or HepG2 cells [54]. For disruption of the PXMP2 gene, we used the online CRISPR tool (http://crispr.mit.edu/) to design two sets of complementary oligonucleotides coding for different guide RNAs targeted to two different protospacer adjacent motif (PAM) sites in exon 2 of the $P X M P 2$ gene, i.e. 5'-TGG at position c.210_212 and 5'-AGG at position c.214_216. For disruption of the PEX11B gene, we designed two sets of complementary oligonucleotides coding for two different guide RNAs targeted to two different PAM sites in exon 2 of the PEX11B gene, i.e. 5'-AGG at position c.63_65 and 5'-AGG at position c.115_117. Each set of complementary oligonucleotides (sequences available on request) was annealed and subsequently cloned into the pX458(-pSpCas9(BB)2A-GFP) plasmid [53] followed by Sanger sequencing of the insert to confirm the correct sequence. DD-myc-DAO Flp-In T-REx 293 or HepG2 cells were transfected with $2 \mu \mathrm{g}$ of plasmid, and single GFP-positive cells were sorted into wells of a 96-well plate using FACS flow cytometry (S800H Cell Sorter, Sony) as described [53]. To create a double $P X M P 2 / P E X 11 B$ knockout cell line, we introduced a $P E X 11 B$ gene knockout in the $\triangle P X M P 2$ DD-myc-DAO Flp-In T-REx 293 clone A cells. After 3-4 weeks, DNA was isolated from the 
expanded clonal cells and exon 2 of the $P X M P 2$ gene and/or exon 2 of the $P E X 11 B$ gene was PCR-amplified using Phire Hot Start II DNA polymerase (Thermo Fisher Scientific) according to the manufacturer's instructions and subsequently Sanger sequenced.

\subsection{Plasmids}

The plasmids encoding po-roGFP2 (pMF1706) [55], mt-roGFP2 (pMF1762) [55], croGFP2 (pMF1707) [55], po-roGFP2-Orp1 (pMF1835) [4], mt-roGFP2-Orp1 (pMF1833) [4], c-roGFP2-Orp1 (pMF1834) [4], HsPEX14-EGFP (pMF120) [56], HsPEX5-mCherry (pMN78) [57], HsPEX5-EGFP (pMN65) [57], or GFP ${ }_{\mathrm{Nb}}-\mathrm{PM}$ (pMF1968) [52] have been described elsewhere. The plasmid coding for PTS2-EGFP (pLA94) was generated by ligating a linker,

prepared from the annealed oligonucleotides 5'agctgaagcttgccaccatgcatcggetgcaggtggtgctgggecacctggecggecgaccegagtcgagctccgcgetgcaagec gcgecttgctcg-3' and 5' - gatccgagcagggcgcggcttgcagcgeggagctcgactcgggtcggccggccaggtggeccagcaccacctgcagccgatgcatggtggcaagcttc-3', into the Hind III/Bam HI-digested pEGFP-N1 vector (Clontech, 6085-1). The plasmid coding for non-tagged HsPEX14 (pMN33) was constructed by amplifying the corresponding cDNA via PCR (primers: 5'gggaagatctatggcgtcctcggagcag-3' and 5'-gagcagggcggccgcctagtcccgctcactctc-3') and ligating the $B g l \mathrm{II} / N o t$ I-digested PCR-product into $B g l \mathrm{II} / N o t$ I-restricted pEGFP-N1.

\subsection{Antibodies}

The rabbit polyclonal antisera against human PEX13 and PEX14 have been described elsewhere [56]. The mouse monoclonal anti-myc antibody was produced from the MYC 19E10.2 cell line (ATCC, CRL-1729). The following antibodies were commercially obtained: the primary rabbit polyclonal antibodies to human ACAA1 (Atlas Antibodies, HPA007244), human DAO (Sigma, HPA038654), human catalase (Calbiochem, 219010), human HsPEX11B (Sigma, HPA050104), human PXMP2 (Proteintech, 24801-1-AP), human HSD17B4 (Proteintech, 15116-1-AP), human TOMM22 (Sigma, HPA003037), and rat PMP70 (Sigma, P0497); the mouse monoclonal antibody to chicken TUBA (Sigma, T9026); the goat anti-rabbit IgGs conjugated to Alexa Fluor 488 (Invitrogen, A11070), Texas Red (Calbiochem, 401355), or alkaline phosphatase (Sigma, A3687); the goat anti-mouse IgGs conjugated to Texas Red (Calbiochem, 401230).

\subsection{Enrichment of integral membrane proteins for immunoblot analysis}


To enrich integral membrane proteins, total cell lysates were subjected to sodium carbonate extraction [58]. Briefly, 5-10 x $10^{6}$ cells were lysed in $6 \mathrm{ml}$ of $100 \mathrm{mM} \mathrm{Na}_{2} \mathrm{CO}_{3}(\mathrm{pH}$ 11.5 ), stirred at $0^{\circ} \mathrm{C}$ for 30 minutes, centrifuged for 1 hour at $100,000 \mathrm{xg}$, and the corresponding pellets were processed for SDS-PAGE/Western blotting. To load equal amounts of integral membrane proteins in each lane, the total protein content was measured in the whole cell lysate fractions and the pellets were resuspended in equivalent volumes of SDS-PAGE solubilization buffer.

\subsection{Fractionation of Flp-In T-REx 293 cells}

Fractionations of Flp-In T-REx 293 cells were performed as described earlier [59] with minor modification. Briefly, approximately $60 \times 10^{6}$ trypsin-freed cells were resuspended in precooled $\left(4^{\circ} \mathrm{C}\right)$ homogenization buffer $(250 \mathrm{mM}$ sucrose, $5 \mathrm{mM}$ MOPS (pH 7.2), $1 \mathrm{mM}$ EDTA $(\mathrm{pH} 7.2), 1 \mathrm{mM}$ dithiothreitol, $0.1 \%(\mathrm{v} / \mathrm{v})$ ethanol, and a protease inhibitor mixture (Sigma, P2714)) and homogenized (10 strokes) using a stainless steel tissue grinder (Kontes, 8853100007). A supernatant resulting from a low speed centrifugation $(1500 \times \mathrm{g}, 10 \mathrm{~min})$ was loaded on a continuous Nycodenz gradient (density range: $1.04-1.36 \mathrm{~g} / \mathrm{ml} ; 5 \mathrm{mM}$ MOPS buffer (pH 7.2) containing $1 \mathrm{mM}$ EDTA (pH 7.2) and $0.1 \%(\mathrm{v} / \mathrm{v})$ ethanol) and spun for 1 hour at 100,000 $\mathrm{g}\left(4^{\circ} \mathrm{C}\right)$. One $\mathrm{ml}$ fractions were collected, the refractive indices were determined with an ATAGO 5000 hand-held refractometer (Thermo Fisher Scientific), and the densities $(\mathrm{g} / \mathrm{ml})$ were calculated by using the formula $3.242 \mathrm{x}$ refractive index -3.323 . Next, $500 \mu \mathrm{l}$ of each fraction was processed for immunoblotting.

\section{7. mRNA expression measurements}

Total RNA was extracted from control and $\triangle$ PEX11B DD-myc-DAO Flp-In T-REx 293 cells by using the Tri Reagent (Sigma, T9524). Reverse transcription of total RNA was done by using the QuantiTect Reverse Transcription Kit (Qiagen, 205310). Real-time PCR was performed on a LightCycler instrument (Roche) using the LightCycler 480 SYBR Green I Master kit (Roche, 04707516001) in combination with gene-specific primer pairs (PEX11A: 5'-tcagagccactcagtacaca-3' (forward) and 5'-aataaatcacacggttcagg-3' (reverse); PEX11B: 5'ggtccgcttcagtgctca-3' (forward) and 5'-ggctgactcaagggcatc-3'(reverse); Sigma). All samples were analyzed in triplicate. The LightCycler 480 Software was used to analyze the data, and the amplification efficiency was determined with LinRegPCR [60]. The PEX11A and PEX11B mRNA expression levels were corrected for the geometric mean of the housekeeping genes 
PPIB (peptidylprolyl isomerase B), RPLP0 (ribosomal protein lateral stalk subunit P0), and $\operatorname{ACTB}(\beta$-actin).

\subsection{Statistical analysis}

Statistics were performed on the VassarStats statistical computation website (http://VassarStats.net). One-way analysis of variance was used to determine the differences among independent groups of numerical values, and individual differences were further explored with a Student's t-test. The significance levels were set at $\mathrm{p}<0.01$.

\section{Results}

\subsection{Generation and validation of PXMP2/PEX11B single and double knockout DD-myc- DAO Flp-In T-REx 293 cell lines}

To investigate the potential role of PXMP2 and PEX11B in $\mathrm{H}_{2} \mathrm{O}_{2}$ permeation across the peroxisomal membrane, we selectively disrupted the corresponding genes in the recently established DD-myc-DAO Flp-In-T-REx 293 cell line [4] by using the CRISPR-Cas9 technology [53]. This cell line is derived from HEK-293 cells engineered for the rapid generation of stable transgenic cell lines exhibiting doxycycline (DOX)-inducible expression of a protein-of-interest (in casu DD-myc-DAO) from a specific genomic location (Thermo Fischer Scientific). DD-myc-DAO is a destabilization domain (DD)- and c-myc epitope-tagged version of D-amino acid oxidase (DAO), a bona fide peroxisomal enzyme that catalyzes the oxidative deamination of neutral and polar D-amino acids to their corresponding imino acids with stoichiometric production of $\mathrm{H}_{2} \mathrm{O}_{2}$ [61]. Proteins fused to the DD domain are rapidly degraded in mammalian cells, unless the stabilizing compound Shield1 is added to the cell culture medium [62]. The rationale behind this already validated cell model is that (i) in the presence of DOX and Shield1, DD-myc-DAO is expressed and stabilized in the cytosol, thereby allowing its import and accumulation into peroxisomes, and (ii) upon DOX and Shield1 withdrawal, the residual pool of cytosolic DD-myc-DAO is rapidly degraded [4]. Importantly, to exclude non-specific effects due to unpredictable off-target editing, two knock-out clones created with different sets of guide RNAs were analyzed for each type of cell line (Table 1).

To verify that the CRISPR-Cas9-mediated disruptions of the PXMP2 and PEX11B loci indeed resulted in the absence of these proteins in the single and double knockout (DKO) cell lines, total cell lysates were first subjected to sodium carbonate extraction to enrich integral 
membrane proteins [58]. This enrichment was necessary to obtain in the subsequent immunoblot experiments signals of sufficient strength for reliable analysis. By employing this approach, the correctness of all cell lines could be confirmed at the protein level (Fig. 1). In addition, immunofluorescence microscopy demonstrated that CRISPR-Cas9 editing and the subsequent clonal selection and expansion of the knockout cells did neither affect the inducibility nor the localization of DD-myc-DAO in any of the cell lines (see Figs. 2 and S1 for the A and B clones, respectively). As documented in mouse liver [42], cultured human primary skin fibroblasts [44], and mouse keratinocytes [63], loss of PEX11B in DD-myc-DAO Flp-In T-REx 293 cells also resulted in a clear decrease in peroxisome abundance $(5.60 \pm 2.62$ peroxisomes $/ 100 \mu \mathrm{m}^{2}$ section surface area; $\left.\mathrm{n}=40\right)$ compared to control cells $(14.07 \pm 4.40$ peroxisomes $/ 100 \mu \mathrm{m}^{2}$ section surface area; $\mathrm{n}=20$ ) (Figs. 2 and $\mathrm{S} 1$; compare the two lower and two upper panels). Unexpectedly, inactivation of PEX11B resulted in a slightly altered staining pattern of the peroxisomal marker protein PEX14 (Figs. 2 and S1), a finding that is explored in more depth in the second half of the Results section.

\subsection{Effects of PXMP2 and PEX11B inactivation on subcellular redox balance}

To investigate how inactivation of PXMP2 and PEX11B affects the redox balance at the subcellular level, control as well as PXMP2/PEX11B single and DKO DD-myc-DAO Flp-In T-REx 293 cells were transfected with a plasmid encoding either peroxisomal (po), cytosolic (c-), or mitochondrial (mt-) roGFP2 or roGFP2-Orp1 [4,55]. RoGFP2 is a redox-sensitive green fluorescent protein that equilibrates with the glutathione redox couple, thereby providing a readout for local changes in the glutathione disulfide (GSSG, oxidized glutathione) to glutathione tripeptide (GSH, reduced glutathione) ratios [64]; and roGFP2-Orp1, a fusion protein between roGFP2 and the yeast peroxidase Orp1, functions as a $\mathrm{H}_{2} \mathrm{O}_{2}$ sensor [65]. Fusion of Orp1 to roGFP2 creates a redox relay in which the peroxidase efficiently transfers oxidizing equivalents from $\mathrm{H}_{2} \mathrm{O}_{2}$ to roGFP2 [65]. For a better understanding of the results obtained with these sensors, it is essential to know that (i) roGFP2 contains two engineered cysteine residues on adjacent surface-exposed $\beta$-strands that, upon disulfide bond formation, increase the protein's excitation peak near $400 \mathrm{~nm}$ at the expense of the peak near $480 \mathrm{~nm}$ [64], (ii) roGFP2 and roGFP2-Orp1 display the same spectral properties [66], and (iii) measuring the fluorescence emission intensities (around $510 \mathrm{~nm}$ ) of roGFP2 and roGFP2-Orp1 upon excitation at 400 and $480 \mathrm{~nm}$ provides insight into the local GSSG/GSH ratios and $\mathrm{H}_{2} \mathrm{O}_{2}$ levels, respectively [67]. 
We found that inactivation of PXMP2 or PEX11B did not alter the peroxisomal GSSG/GSH ratios, at least not under basal conditions (Fig. 3A). However, in the DKO cell lines, the peroxisomal probe was slightly but significantly less oxidized (Fig. 3B). Inactivation of PXMP2 or PEX11B did not result in any significant differences in the cytosolic or mitochondrial glutathione redox balance, neither in the single nor in the DKO cell lines (Fig. S2). In line with this, no alterations in the cytosolic or mitochondrial $\mathrm{H}_{2} \mathrm{O}_{2}$ levels could be detected in any of these cell lines (Fig. S3). Unfortunately, given that peroxisomally located roGFP2-Orp1 is already virtually completely oxidized in control [4] as well as in PXMP2/PEX11B single or DKO (data not shown) DD-myc-DAO Flp-In T-REx 293 cells, it is not possible to draw conclusions whether the absence of PXMP2 and/or PEX11B has any effect on peroxisomal $\mathrm{H}_{2} \mathrm{O}_{2}$ levels. In summary, these data indicate that inactivation of PXMP2 or PEX11B has no impact on the peroxisomal, mitochondrial, and cytosolic redox balance, at least not under basal conditions. However, co-inactivation of PXMP2 and PEX11B leads to a small but significant decrease in the peroxisomal GSSG/GSH balance.

\section{3. $\mathrm{H}_{2} \mathrm{O}_{2}$ efficiently permeates the peroxisomal membrane in the absence of PXMP2 and PEX11B}

To assess the importance of PXMP2 and PEX11B in $\mathrm{H}_{2} \mathrm{O}_{2}$ permeation across the peroxisomal membrane, we compared the response kinetics of c-roGFP2-Orp1 in control and PXMP2/PEX11B single or DKO DD-myc-DAO Flp-In T-REx 293 cells upon addition of DAla. The reasoning behind this experiment is that, in case PXMP2 or PEX11B are important for $\mathrm{H}_{2} \mathrm{O}_{2}$ permeation, the oxidation state of c-roGFP2-Orp1 will increase at a slower rate in the deletion cells as compared to control cells. To exclude the possibility that potential differences in the response kinetics are due to differences in DD-myc-DAO expression levels, the expression levels of DD-myc-DAO were monitored in each experiment. The combined data of at least three independent experiments show that the response profiles of c-roGFP2-Orp1 are similar in all cell lines (see Figs. 4, S5, and S6 for the PXMP2-, PEX11B-, or PXMP2/PEX11Bdeficient cell lines, respectively). Hence, neither PXMP2 nor PEX11B are essential for $\mathrm{H}_{2} \mathrm{O}_{2}$ permeation across the peroxisomal membrane.

\subsection{Loss of PEX11B causes partial localization of peroxisomal proteins to mitochondria}

As aforementioned, inactivation of PEX11B resulted in a slightly different staining pattern for PEX14 as compared to that of control or $\triangle$ PXMP2 Flp-In T-REx 293 cells (Figs. 2 and S1). To determine whether or not this distinct staining pattern reflected a partial localization 
of PEX14 to mitochondria, a phenomenon known to occur in mammalian cells with defective peroxisomal membrane biogenesis [68], the cells were stained with MitoTracker Red. These experiments showed that inactivation of PEX11B in control or $\triangle \mathrm{PXMP} 2$ cells indeed leads to a partial mitochondrial localization of PEX14. Interestingly, with the exception of DD-mycDAO (Fig. 2), also all other tested peroxisomal membrane and matrix proteins displayed a weak but consistent localization to mitochondria in these cells, regardless of whether they were endogenously (e.g., PMP70, catalase, HSD17B4) or exogenously (e.g., po-roGFP2, and PTS2GFP) expressed (Figs. 5 and S7). This result was unexpected, especially for the matrix proteins, which are normally targeted to peroxisomes by either a C-terminal (e.g., catalase, HSD17B4, po-roGFP2) or N-terminal (e.g., PTS2-GFP) targeting signal (termed PTS1 and PTS2, respectively). A possible explanation for the apparently aberrant behavior of the PTS1 protein DD-myc-DAO is that, after the chase period of 1 day, its expression levels are relatively low [4], thereby likely resulting in mitochondrial DD-myc-DAO concentrations that are below the detection limit.

In an attempt to substantiate the fluorescence microscopy data, $1500 \mathrm{x} g$ supernatants of control and $\triangle$ PEX11B Flp-In T-REx 293 cell lysates were subjected to Nycodenz density gradient centrifugation and the banding patterns of peroxisomes and mitochondria were visualized by Western blot analysis with antibodies specific for PEX13 and TOMM22, respectively. Surprisingly, these analyses revealed that inactivation of PEX11B changed the peroxisomal peak density from $1.19 \mathrm{~g} / \mathrm{ml}$ (fraction 12 ) to a lighter density of $1.15 \mathrm{~g} / \mathrm{ml}$ (fraction 14) (Fig. 6, panels A and B). This observation was confirmed by immunostaining a select set of fractions with antibodies specific for PEX14, ACAA1, HSD17B4, or catalase (Fig. 6C). Inactivation of PEX11B did not (or only very modestly) change the banding patterns of TOMM22 (mitochondria) and TUBA (cytosol) (Fig. 6C). Unfortunately, given that the peroxisomal and mitochondrial peak fractions display a significant overlap in the PEX11Bdeficient cells (Fig. 6B), it is not possible to use the density gradient data to document the mitochondrial localization of peroxisomal proteins in these cells. Note also that in the control cells there is a peroxisome fraction banding at $1.14 \mathrm{~g} / \mathrm{ml}$ (fraction 15) (Fig. 6B), an observation in line with previous studies showing the presence of regular $(1.20 \mathrm{~g} / \mathrm{ml})$ and light $(1.14 \mathrm{~g} / \mathrm{ml})$ density peroxisomes in human HepG2 cells [69].

Finally, we could demonstrate that inactivation of PEX11B also leads to a partial mitochondrial localization of peroxisomal proteins in human HepG2 cells (Fig. S8), indicating 
that this phenomenon is not cell type-specific. The validation data of the HepG2 cell lines are shown in Fig. S9.

\subsection{The mitochondrial pool of po-roGFP in $\triangle$ PEX11B cells is exposed to an oxidizing environment}

Upon measurement of the redox equilibrium of the mitochondrial pool of po-roGFP2 in $\triangle$ PEX11B Flp-In T-REx 293 cells, we unexpectedly observed that this protein was significantly more oxidized than its peroxisomal counterpart or its variants that are located in the mitochondrial matrix or the cytosol (Fig. 7). Similar observations were recorded in DKO cells (Fig. S10). Given that it is well-known that the mitochondrial intermembrane space (IMS) is considerably more oxidizing than the cytosol and the mitochondrial matrix [70,71], these findings strongly indicate that mitochondria-associated po-roGFP2 is located in the IMS. For an in-depth interpretation of this result, we refer the reader to the discussion.

\section{Discussion}

In this study, we sought to explore the involvement of PXMP2 and PEX11B, two widely expressed PMPs with potential pore-forming properties [28-33], in $\mathrm{H}_{2} \mathrm{O}_{2}$ permeation across the peroxisomal membrane. Therefore, we generated mutant DD-myc-DAO Flp-In T-REx 293 cell lines in which the genes coding for PXMP2 or PEX11B were individually or simultaneously disrupted by the CRISPR-Cas9 gene editing technology. From the data presented, it is evident that neither PXMP2 nor PEX11B are essential for efficient $\mathrm{H}_{2} \mathrm{O}_{2}$ permeation across the peroxisomal membrane (Figs. 4, S5, and S6). In this context, it is relevant to point out that roGFP2-Orp1 responds quite rapidly (within minutes) and specifically to localized bursts of $\mathrm{H}_{2} \mathrm{O}_{2}$ [72], thereby ruling out that potential differences in the response kinetics between the different cell lines were not detected because of the methodological approach employed. In addition, given that $\mathrm{H}_{2} \mathrm{O}_{2}$ production by DD-myc-DAO can only occur after D-Ala uptake into peroxisomes, it is evident that both PMPs are also not essential for the permeation of D-Ala across the peroxisomal membrane.

Importantly, based on previous studies reporting that the mammalian peroxisomal membrane contains at least two types of pore-forming channels [35,39], our results cannot be interpreted as evidence that PXMP2 or PEX11B do not have any role in the transmembrane transport of D-Ala or $\mathrm{H}_{2} \mathrm{O}_{2}$. Here, it is interesting to note that co-inactivation of PXMP2 and PEX11B, but not of any of these PMPs individually, leads to a small but significant decrease 
in the peroxisomal GSSG/GSH balance (Fig. 3B). On one hand, this finding may indicate that PXMP2 and PEX11B have a redundant transport specificity for not-yet-identified substrates, cofactors, or metabolites involved in processes controlling peroxisomal ROS production (e.g., $\beta$-oxidation). On the other hand, one of these proteins (e.g., PEX11B) may directly (e.g., through protein-protein interactions) or indirectly (e.g., through changes in membrane curvature [29]) influence the activity of other yet-to-be-identified transporters sharing overlapping substrate specificity with the other inactivated PMP (e.g., PXMP2).

An interesting side observation of this study is that loss of PEX11B causes partial localization of peroxisomal membrane and matrix proteins to mitochondria (Figs. 2, 5, S1, S7, and S8), a phenomenon not previously reported by others [42,44]. In addition, it was quite unexpected to see that the mitochondrial pool of po-roGFP2 in $\triangle \mathrm{PEX} 11 \mathrm{~B}$ cells is considerably more oxidized than its respective variants that are localized in the cytosol or the mitochondrial matrix (Figs. 7 and S10). Based on previous work demonstrating that the IMS is a more oxidizing environment than the mitochondrial matrix or the cytosol [70,71], this finding points towards an IMS localization of mitochondria-associated po-roGFP2. However, to unambiguously confirm this hypothesis, immuno-electron microscopy experiments should be performed. If so, this would imply that loss of PEX11B activity results in the formation of a functional peroxisomal matrix protein translocon in the outer mitochondrial membrane. The molecular details underlying this event remain to be determined. However, given that (i) in Pichia pastoris, the minimal translocon for peroxisomal matrix proteins consists of the PTS receptors and PEX14 [73], (ii) loss of PEX11B in DD-myc-DAO Flp-In T-REx 293 or human HepG2 cells causes partial mitochondrial localization of PEX14 (Figs. 2, 5, S1, and S8), and (iii) redirection of ectopically expressed PEX14 to the plasma membrane also recruits a portion of PEX5 to this subcellular location (Fig. S11), it is tempting to speculate that sorting of PEX14 to mitochondria represents the initial seeding event. Unfortunately, due to a predominantly cytosolic localization of endogenous PEX5 [74], we were not able to provide direct evidence that a small portion of this cycling receptor does also associate with mitochondria in $\triangle \mathrm{PEX} 11 \mathrm{~B}$ cells (data not shown). However, we could obtain evidence that overexpression of PEX14 in these cells did promote the recruitment of PEX5-EGFP to mitochondria (Fig. S12). In case our hypothesis is correct, small amounts of mitochondria-associated peroxisomal matrix proteins should also be found in other cell lines in which PEX14 is localized to mitochondria (e.g., in cells lacking peroxisomal remnants) ([68]; and references therein). However, to the best of our knowledge, such data have not yet been reported. Once again, this may have gone unnoticed 
due to the abundant presence of cytosolically localized peroxisomal matrix proteins in such cells [75]. Finally, unlike in cultured primary skin fibroblasts derived from a patient with a homozygous c.64C $>$ T non-sense mutation in the PEX11B gene [44], we did not find PEX11Bdeficient DD-myc-DAO Flp-In T-REx 293 or human HepG2 cells showing a cytosolic localization of catalase. A possible explanation for these apparently conflicting data may be that passaging of human primary skin fibroblasts shifts the cytosolic redox balance to a more oxidized state [55], a condition in which catalase is much more likely to remain unimported in the cytosol [52].

The findings presented in this study open up an intriguing set of new questions. First, in case PXMP2 and PEX11B are not essential for $\mathrm{H}_{2} \mathrm{O}_{2}$ permeation across the peroxisomal membrane, which other PMPs exhibit peroxiporin-like properties? Indeed, given that the peroxisomal membrane serves as a significant permeability barrier for $\mathrm{H}_{2} \mathrm{O}_{2}$ [24], such proteins have to be present. Potential candidate proteins are the widely expressed proteins PXMP4 (also known as PMP24 [76]) and SCL25A17 (also known as PMP34 [77]). PXMP4 is a protein of unknown function that shows similarity with certain bacterial permeases [78], and SCL25A17 is a peroxisomal protein that belongs to the family of mitochondrial solute carriers and whose substrate specificity is not yet clear (it was first described as an ATP transporter [79], later it became clear that this protein also plays a role in the breakdown of phytanic and pristanic acid [2], and another report presents this PMP as a transporter of nucleotide-based molecules such as CoA, FAD, FMN, and AMP [80]). In addition, given that (i) PEX11A contains the channel signature sequence of the transient receptor potential ion channel TRPM8 [33], (ii) this peroxin is also expressed in some neuronal cell types [81], and (iii) HEK-293 cells have neuronal lineage cell properties [70], PEX11A may also be a potential candidate, at least in the Flp-In TREx cell line under study. However, given that PEX11A is apparently not highly expressed in HEK-293 cells (its mRNA and protein levels are, respectively, approximately 5-fold (Fig. S13) and 22-fold [83] less than those of PEX11B), this possibility is rather unlikely. Second, what are the molecular mechanisms underlying the IMS localization of po-roGFP2, a redox-sensitive reporter protein that is normally imported into the lumen of peroxisomes [55]? Addressing this knowledge gap may contribute more insight into the minimal translocon composition for peroxisomal matrix protein import in mammalian cells. Third, does the weak but consistent localization of peroxisomal membrane and matrix proteins to mitochondria cause mitochondrial dysfunction and, if so, how does this contribute to the clinical phenotype of patients with PEX11B defects? And last, how does PEX11B prevent the mitochondrial localization of 
peroxisomal proteins, and is this a PEX11B-specific phenomenon or can loss of PEX11A or PEX11G result in a similar phenotype? Answers to these questions will provide crucial insights into the molecular mechanisms underlying peroxisomal $\mathrm{H}_{2} \mathrm{O}_{2}$-mediated redox signaling and the role of PEX11B in peroxisome biogenesis in health and disease.

\section{Acknowledgments}

We thank Ms. Iulia Revenco for critically reading the manuscript.

\section{Funding}

This work was supported by the KU Leuven [OT/14/100, PDM/18/188], the Research Foundation - Flanders [G095315N], the ERA-Net for Research Programmes on Rare Diseases [PERescue], and H2020-MSCA-ITN [812968].

\section{Author contributions}

CL, PVV, and MF conceived the study concept and design; MF, MB, PVV, HW, and CL provided the study materials, reagents, instrumentation, and other analysis tools; CL, SP, and JK carried out the experiments; CL, HW, PVV, and MF analyzed the data; MF, PVV, and HW provided the supervision; $C L$ and MF generated the figures and wrote the original draft; and all authors reviewed and approved the final manuscript. 


\section{References}

[1] Wanders RJ, Waterham HR (2006) Biochemistry of mammalian peroxisomes revisited. Annu Rev Biochem 75, 295-332.

[2] Van Veldhoven PP (2010) Biochemistry and genetics of inherited disorders of peroxisomal fatty acid metabolism. J Lipid Res 51, 2863-2895.

[3] Fransen M, Nordgren M, Wang B, Apanasets O (2012) Role of peroxisomes in ROS/RNS-metabolism: implications for human disease. Biochim Biophys Acta 1822, $1363-1373$.

[4] Lismont C, Nordgren M, Brees C, Knoops B, Van Veldhoven PP, Fransen M (2019) Peroxisomes as modulators of cellular protein thiol oxidation: a new model system. Antioxid Redox Signal 30, 22-39.

[5] Sies H, Berndt C, Jones DP (2017) Oxidative Stress. Annu Rev Biochem 86, 715-748.

[6] Fransen M, Lismont C (2019) Redox signaling from and to peroxisomes: progress, challenges, and prospects. Antioxid Redox Signal 30, 95-112.

[7] Li Y, Tharappel JC, Cooper S, Glenn M, Glauert HP, Spear BT (2000) Expression of the hydrogen peroxide-generating enzyme fatty acyl CoA oxidase activates NF-kappaB. DNA Cell Biol 19, 113-120.

[8] Ruiz-Ojeda FJ, Gomez-Llorente C, Aguilera CM, Gil A, Rupérez AI (2016) Impact of 3amino-1,2,4-triazole (3-AT)-derived increase in hydrogen peroxide levels on inflammation and metabolism in human differentiated adipocytes. PLoS One 11, e0152550.

[9] Heit C, Marshall S, Singh S, Yu X, Charkoftaki G, Zhao H, Orlicky DJ, Fritz KS, Thompson DC, Vasiliou V (2017) Catalase deletion promotes prediabetic phenotype in mice. Free Radic Biol Med 103, 48-56.

[10] Diano S, Liu ZW, Jeong JK, Dietrich MO, Ruan HB, Kim E, Suyama S, Kelly K, Gyengesi E, Arbiser JL, Belsham DD, Sarruf DA, Schwartz MW, Bennett AM, Shanabrough M, Mobbs CV, Yang X, Gao XB, Horvath TL. Peroxisome proliferationassociated control of reactive oxygen species sets melanocortin tone and feeding in dietinduced obesity. Nat Med 17, 1121-1127.

[11] Zhang J, Tripathi DN, Jing J, Alexander A, Kim J, Powell RT, Dere R, Tait-Mulder J, Lee JH, Paull TT, Pandita RK, Charaka VK, Pandita TK, Kastan MB, Walker CL (2015) ATM functions at the peroxisome to induce pexophagy in response to ROS. Nat Cell Biol $17,1259-1269$. 
[12] Carter AB, Tephly LA, Venkataraman S, Oberley LW, Zhang Y, Buettner GR, Spitz DR, Hunninghake GW (2004) High levels of catalase and glutathione peroxidase activity dampen $\mathrm{H}_{2} \mathrm{O}_{2}$ signaling in human alveolarmacrophages. Am J Respir Cell Mol Biol 31, 43-53.

[13] Brown MR, Miller FJ Jr, Li WG, Ellingson AN, Mozena JD, Chatterjee P, Engelhardt JF, Zwacka RM, Oberley LW, Fang X, Spector AA, Weintraub NL (1999) Overexpression of human catalase inhibits proliferation and promotes apoptosis in vascular smooth muscle cells. Circ Res 85, 524-533.

[14] Onumah OE, Jules GE, Zhao Y, Zhou L, Yang H, Guo Z (2009) Overexpression of catalase delays G0/G1 - to S-phase transition during cell cycle progression in mouse aortic endothelial cells. Free Radic Biol Med 46, 1658-1667.

[15] Glorieux C, Dejeans N, Sid B, Beck R, Calderon PB, Verrax J (2011) Catalase overexpression in mammary cancer cells leads to a less aggressive phenotype and an altered response to chemotherapy. Biochem Pharmacol 82, 1384-1390.

[16] Bracalente C, Ibañez IL, Berenstein A, Notcovich C, Cerda MB, Klamt F, Chernomoretz A, Durán H (2016) Reprogramming human A375 amelanotic melanoma cells by catalase overexpression: Upregulation of antioxidant genes correlates with regression of melanoma malignancy and with malignant progression when downregulated. Oncotarget 7, 41154-41171.

[17] Legakis JE, Koepke JI, Jedeszko C, Barlaskar F, Terlecky LJ, Edwards HJ, Walton PA, Terlecky SR (2002) Peroxisome senescence in human fibroblasts. Mol Biol Cell 13, 4243-4255.

[18] Chen X, Liang H, Van Remmen H, Vijg J, Richardson A (2004) Catalase transgenic mice: characterization and sensitivity to oxidative stress. Arch Biochem Biophys 422, 197-210.

[19] Li X, Chen H, Epstein PN (2006) Metallothionein and catalase sensitize to diabetes in nonobese diabetic mice: reactive oxygen species may have a protective role in pancreatic beta-cells. Diabetes 55, 1592-1604.

[20] Elsner M, Gehrmann W, Lenzen S (2011) Peroxisome-generated hydrogen peroxide as important mediator of lipotoxicity in insulin-producing cells. Diabetes 60, 200-218.

[21] Gehrmann W, Würdemann W, Plötz T, Jörns A, Lenzen S, Elsner M (2015) Antagonism between saturated and unsaturated fatty acids in ROS mediated lipotoxicity in rat insulinproducing cells. Cell Physiol Biochem 36, 852-865. 
[22] Ho YS, Xiong Y, Ma W, Spector A, Ho DS (2004) Mice lacking catalase develop normally but show differential sensitivity to oxidant tissue injury. J Biol Chem 279, 32804-32812.

[23] Bienert GP, Schjoerring JK, Jahn TP (2006) Membrane transport of hydrogen peroxide. Biochim Biophys Acta 1758, 994-1003.

[24] Antunes F, Cadenas E (2000) Estimation of $\mathrm{H}_{2} \mathrm{O}_{2}$ gradients across biomembranes. FEBS Lett 475, 121-126.

[25] Branco MR, Marinho HS, Cyrne L, Antunes F (2004) Decrease of $\mathrm{H}_{2} \mathrm{O}_{2}$ plasma membrane permeability during adaptation to $\mathrm{H}_{2} \mathrm{O}_{2}$ in Saccharomyces cerevisiae. J Biol Chem 279, 6501-6506.

[26] Henzler T, Steudle E (2000) Transport and metabolic degradation of hydrogen peroxide in Chara corallina: model calculations and measurements with the pressure probe suggest transport of $\mathrm{H}_{2} \mathrm{O}_{2}$ across water channels. J Exp Bot 51, 2053-2066.

[27] Antonenkov VD, Hiltunen JK (2012) Transfer of metabolites across the peroxisomal membrane. Biochim Biophys Acta 1822, 1374-1386.

[28] Rokka A, Antonenkov VD, Soininen R, Immonen HL, Pirilä PL, Bergmann U, Sormunen RT, Weckström M, Benz R, Hiltunen JK (2009) Pxmp2 is a channel-forming protein in mammalian peroxisomal membrane. PLoS One 4, e5090.

[29] Opaliński Ł, Kiel JA, Williams C, Veenhuis M, van der Klei IJ (2011) Membrane curvature during peroxisome fission requires Pex11. EMBO J 30, 5-16.

[30] Williams C, Opalinski L, Landgraf C, Costello J, Schrader M, Krikken AM, Knoops K, Kram AM, Volkmer R, van der Klei IJ (2015) The membrane remodeling protein Pex11p activates the GTPase Dnmlp during peroxisomal fission. Proc Natl Acad Sci USA 112, 6377-6382.

[31] Honsho M, Yamashita S, Fujiki Y (2016) Peroxisome homeostasis: Mechanisms of division and selective degradation of peroxisomes in mammals. Biochim Biophys Acta 1863, 984-991.

[32] Gualdron-López M, Vapola MH, Miinalainen IJ, Hiltunen JK, Michels PA, Antonenkov VD (2012) Channel-forming activities in the glycosomal fraction from the bloodstream form of Trypanosoma brucei. PLoS One 7, e34530.

[33] Mindthoff S, Grunau S, Steinfort LL, Girzalsky W, Hiltunen JK, Erdmann R, Antonenkov VD (2016) Peroxisomal Pex11 is a pore-forming protein homologous to TRPM channels. Biochim Biophys Acta 1863, 271-283. 
[34] Vapola MH, Rokka A, Sormunen RT, Alhonen L, Schmitz W, Conzelmann E, Wärri A, Grunau S, Antonenkov VD, Hiltunen JK (2014) Peroxisomal membrane channel Pxmp2 in the mammary fat pad is essential for stromal lipid homeostasis and for development of mammary gland epithelium in mice. Dev Biol 391, 66-80.

[35] Labarca P, Wolff D, Soto U, Necochea C, Leighton F (1986) Large cation-selective pores from rat liver peroxisomal membranes incorporated to planar lipid bilayers. J Membr Biol 94, 285-291.

[36] Van Veldhoven PP, Just WW, Mannaerts GP (1987) Permeability of the peroxisomal membrane to cofactors of beta-oxidation. Evidence for the presence of a pore-forming protein. J Biol Chem 262, 4310-4318.

[37] Lemmens M, Verheyden K, Van Veldhoven P, Vereecke J, Mannaerts GP, Carmeliet E (1989) Single-channel analysis of a large conductance channel in peroxisomes from rat liver. Biochim Biophys Acta 984, 351-359.

[38] Antonenkov VD, Sormunen RT, Hiltunen JK (2004) The rat liver peroxisomal membrane forms a permeability barrier for cofactors but not for small metabolites in vitro. J Cell Sci $117,5633-5642$.

[39] Antonenkov VD, Rokka A, Sormunen RT, Benz R, Hiltunen JK (2005) Solute traffic across mammalian peroxisomal membrane--single channel conductance monitoring reveals pore-forming activities in peroxisomes. Cell Mol Life Sci 62, 2886-2895.

[40] Chen C, Wang H, Chen B, Chen D, Lu C, Li H, Qian Y, Tan Y, Weng H, Cai L (2019) Pex11a deficiency causes dyslipidaemia and obesity in mice. J Cell Mol Med (in press; doi: $10.1111 / \mathrm{jcmm} .14108)$.

[41] Schrader M, Costello JL, Godinho LF, Azadi AS, Islinger M (2016). Proliferation and fission of peroxisomes - An update. Biochim Biophys Acta 1863, 971-983.

[42] Li X, Baumgart E, Morrell JC, Jimenez-Sanchez G, Valle D, Gould SJ (2002) PEX11 beta deficiency is lethal and impairs neuronal migration but does not abrogate peroxisome function. Mol Cell Biol 22, 4358-4365.

[43] Taylor RL, Handley MT, Waller S, Campbell C, Urquhart J, Meynert AM, Ellingford JM, Donnelly D, Wilcox G, Lloyd IC, Mundy H, FitzPatrick DR, Deshpande C, ClaytonSmith J, Black GC (2017) Novel PEX11B mutations extend the peroxisome biogenesis disorder 14B phenotypic spectrum and underscore congenital cataract as an early feature. Invest Ophthalmol Vis Sci 58, 594-603. 
[44] Ebberink MS, Koster J, Visser G, Spronsen Fv, Stolte-Dijkstra I, Smit GP, Fock JM, Kemp S, Wanders RJ, Waterham HR (2012) A novel defect of peroxisome division due to a homozygous non-sense mutation in the PEX11 $\beta$ gene. J Med Genet 49, 307-313.

[45] Ahlemeyer B, Gottwald M, Baumgart-Vogt E (2012) Deletion of a single allele of the Pex $11 \beta$ gene is sufficient to cause oxidative stress, delayed differentiation and neuronal death in mouse brain. Dis Model Mech 5, 125-140.

[46] Papatheodorou I, Fonseca NA, Keays M, Tang YA, Barrera E, Bazant W, Burke M, Füllgrabe A, Fuentes AM, George N, Huerta L, Koskinen S, Mohammed S, Geniza M, Preece J, Jaiswal P, Jarnuczak AF, Huber W, Stegle O, Vizcaino JA, Brazma A, Petryszak R (2018) Expression Atlas: gene and protein expression across multiple studies and organisms. Nucleic Acids Res 46, D246-D251.

[47] Brees C, Fransen M (2014) A cost-effective approach to microporate mammalian cells with the Neon Transfection System. Anal Biochem 466, 49-50.

[48] Huybrechts SJ, Van Veldhoven PP, Brees C, Mannaerts GP, Los GV, Fransen M (2009) Peroxisome dynamics in cultured mammalian cells. Traffic 10, 1722-1733.

[49] Vancha AR, Govindaraju S, Parsa KV, Jasti M, González-García M, Ballestero RP (2004) Use of polyethyleneimine polymer in cell culture as attachment factor and lipofection enhancer. BMC Biotechnol 4, 23.

[50] Nordgren M, Wang B, Apanasets O, Brees C, Veldhoven PP, Fransen M (2012) Potential limitations in the use of KillerRed for fluorescence microscopy. J Microsc 245, 229-235.

[51] Lismont C, Walton PA, Fransen M (2017) Quantitative monitoring of subcellular redox dynamics in living mammalian cells using roGFP2-based probes. Methods Mol Biol $1595,151-164$.

[52] Walton PA, Brees C, Lismont C, Apanasets O, Fransen M (2017) The peroxisomal import receptor PEX5 functions as a stress sensor, retaining catalase in the cytosol in times of oxidative stress. Biochim Biophys Acta - Mol Cell Res 1864, 1833-1843.

[53] Ran FA, Hsu PD, Wright J, Agarwala V, Scott DA, Zhang F (2013) Genome engineering using the CRISPR-Cas9 system. Nat Protoc 8, 2281-2308.

[54] Klouwer FC, Koster J, Ferdinandusse S, Waterham HR (2017) Peroxisomal abnormalities in the immortalized human hepatocyte (IHH) cell line. Histochem Cell Biol 147, 537541.

[55] Ivashchenko O, Van Veldhoven PP, Brees C, Ho YS, Terlecky SR, Fransen M (2011) Intraperoxisomal redox balance in mammalian cells: oxidative stress and interorganellar cross-talk. Mol Biol Cell 22, 1440-1451. 
[56] Fransen M, Wylin T, Brees C, Mannaerts GP, Van Veldhoven PP (2001) Human Pex 19p binds peroxisomal integral membrane proteins at regions distinct from their sorting sequences. Mol Cell Biol 21, 4413-4424.

[57] Nordgren M, Francisco T, Lismont C, Hennebel L, Brees C, Wang B, Van Veldhoven PP, Azevedo JE, Fransen M (2015) Export-deficient monoubiquitinated PEX5 triggers peroxisome removal in SV40 large T antigen-transformed mouse embryonic fibroblasts. Autophagy 11, 1326-1340.

[58] Fujiki Y, Hubbard AL, Fowler S, Lazarow PB (1982) Isolation of intracellular membranes by means of sodium carbonate treatment: application to endoplasmic reticulum. J Cell Biol 93, 97-102.

[59] Fransen M, Vastiau I, Brees C, Brys V, Mannaerts GP, Van Veldhoven PP (2004) Potential role for Pex19p in assembly of PTS-receptor docking complexes. J Biol Chem 279, 12615-12624.

[60] Ruijter JM, Ramakers C, Hoogaars WM, Karlen Y, Bakker O, van den Hoff MJ, Moorman AF (2009) Amplification efficiency: linking baseline and bias in the analysis of quantitative PCR data. Nucleic Acids Res 37, e45.

[61] Angermüller S, Fahimi HD (1988) Light microscopic visualization of the reaction product of cerium used for localization of peroxisomal oxidases. J Histochem Cytochem 36, 2328.

[62] Banaszynski LA, Chen LC, Maynard-Smith LA, Ooi AG, Wandless TJ (2006) A rapid, reversible, and tunable method to regulate protein function in living cells using synthetic small molecules. Cell 126, 995-1004.

[63] Asare A, Levorse J, Fuchs E (2017) Coupling organelle inheritance with mitosis to balance growth and differentiation. Science 355, 6324.

[64] Hanson GT, Aggeler R, Oglesbee D, Cannon M, Capaldi RA, Tsien RY, Remington SJ (2004) Investigating mitochondrial redox potential with redox-sensitive green fluorescent protein indicators. J Biol Chem 279, 13044-13053.

[65] Gutscher M, Sobotta MC, Wabnitz GH, Ballikaya S, Meyer AJ, Samstag Y, Dick TP (2009) Proximity-based protein thiol oxidation by $\mathrm{H}_{2} \mathrm{O}_{2}$-scavenging peroxidases. J Biol Chem 284, 31532-31540.

[66] Meyer AJ, Dick TP (2010) Fluorescent protein-based redox probes. Antioxid Redox Signal 13, 621-650. 
[67] Meyer AJ, Brach T, Marty L, Kreye S, Rouhier N, Jacquot JP, Hell R (2007) Redoxsensitive GFP in Arabidopsis thaliana is a quantitative biosensor for the redox potential of the cellular glutathione redox buffer. Plant J 52, 973-986.

[68] Sugiura A, Mattie S, Prudent J, McBride HM (2017) Newly born peroxisomes are a hybrid of mitochondrial and ER-derived pre-peroxisomes. Nature 542, 251-254.

[69] Schrader M, Baumgart E, Völk1 A, Fahimi HD (1994) Heterogeneity of peroxisomes in human hepatoblastoma cell line HepG2. Evidence of distinct subpopulations. Eur J Cell Biol 64, 281-294.

[70] $\mathrm{Hu}$ J, Dong L, Outten CE (2008) The redox environment in the mitochondrial intermembrane space is maintained separately from the cytosol and matrix. J Biol Chem 283, 29126-29134.

[71] Kojer K, Bien M, Gangel H, Morgan B, Dick TP, Riemer J (2012) Glutathione redox potential in the mitochondrial intermembrane space is linked to the cytosol and impacts the Mia40 redox state. EMBO J 31, 3169-3182.

[72] Morgan B, Sobotta MC, Dick TP (2011) Measuring EGSH and H2O2 with roGFP2-based redox probes. Free Radic Biol Med 51, 1943-1151.

[73] Ma C, Schumann U, Rayapuram N, Subramani S (2009) The peroxisomal matrix import of Pex8p requires only PTS receptors and Pex14p. Mol Biol Cell 20, 3680-3689.

[74] Dodt G, Gould SJ (1996) Multiple PEX genes are required for proper subcellular distribution and stability of Pex5p, the PTS1 receptor: evidence that PTS1 protein import is mediated by a cycling receptor. J Cell Biol 135, 1763-1774.

[75] Kim PK, Hettema EH (2015) Multiple pathways for protein transport to peroxisomes. J Mol Biol 427, 1176-1190.

[76] Reguenga C, Oliveira ME, Gouveia AM, Eckerskorn C, Sá-Miranda C, Azevedo JE (2009) Identification of a $24 \mathrm{kDa}$ intrinsic membrane protein from mammalian peroxisomes. Biochim Biophys Acta 1445, 337-341.

[77] Wylin T, Baes M, Brees C, Mannaerts GP, Fransen M, Van Veldhoven PP (1998) Identification and characterization of human PMP34, a protein closely related to the peroxisomal integral membrane protein PMP47 of Candida boidinii. Eur J Biochem 258, 332-338.

[78] Visser WF, van Roermund CW, Ijlst L, Waterham HR, Wanders RJ (2007) Metabolite transport across the peroxisomal membrane. Biochem J 401, 365-375. 
[79] Visser WF, van Roermund CW, Waterham HR, Wanders RJ (2002) Identification of human PMP34 as a peroxisomal ATP transporter. Biochem Biophys Res Commun 299, 494-497.

[80] Agrimi G, Russo A, Scarcia P, Palmieri F (2012) The human gene SLC25A17 encodes a peroxisomal transporter of coenzyme A, FAD and NAD ${ }^{+}$. Biochem J 443, 241-247.

[81] Sunkin SM, Ng L, Lau C, Dolbeare T, Gilbert TL, Thompson CL, Hawrylycz M, Dang C (2013) Allen Brain Atlas: an integrated spatio-temporal portal for exploring the central nervous system. Nucleic Acids Res 41, D996-D1008.

[82] Shaw G, Morse S, Ararat M, Graham FL (2002) Preferential transformation of human neuronal cells by human adenoviruses and the origin of HEK293 cells. FASEB J 16, 869871.

[83] Geiger T, Wehner A, Schaab C, Cox J, Mann M (2012) Comparative proteomic analysis of eleven common cell lines reveals ubiquitous but varying expression of most proteins. Mol Cell Proteomics 11, M111.014050. 


\section{Legends to Figures}

Figure 1. Immunoblot validation of the CRISPR-Cas9-edited DD-myc-DAO Flp-In TREx 293 cell lines. Total cell lysates from control (CT), $\triangle \mathrm{PXMP} 2, \triangle \mathrm{PEX} 11 \mathrm{~B}$, or $\triangle$ PXMP2 $\triangle$ PEX11B (DKO) DD-myc-DAO Flp-In T-REx 293 cells, all containing equal amounts of protein, were subjected to sodium carbonate treatment to separate soluble and peripheral proteins from integral membrane proteins. The carbonate-insoluble fractions were subsequently processed for SDS-PAGE, Western blotting, and immunoblot analysis with antisera directed against PXMP2 or PEX11B. The arrows and asterisk mark specific and nonspecific immunoreactive bands, respectively.

Figure 2. Expression and localization of DD-myc-DAO in control and PXMP2/PEX11B single or double knockout DD-myc-DAO Flp-In T-REx 293 cells. Control (CT), $\triangle$ PXMP2 (clone A), $\triangle \mathrm{PEX} 11 \mathrm{~B}$ (clone A), or $\triangle \mathrm{PXMP2} \triangle \mathrm{PEX11B}$ (DKO, clone A) DD-myc-DAO Flp-In T-REx 293 cells were first cultured for three days in the absence (no induction) or presence (induction + chase) of $1 \mu \mathrm{g} / \mathrm{ml}$ DOX and $500 \mathrm{nM}$ Shield1. Next, the cells were cultured for one additional day in medium lacking DOX and Shield1, and subsequently processed for fluorescence microscopy. The cells were stained with mouse anti-myc (myc) and rabbit antiPEX14 (14) antibodies followed by anti-mouse TxRed and anti-rabbit Alexa 488-conjugated secondary antibodies. The nuclei were counterstained with DAPI. Representative images are shown. The boxed areas in the upper panels are enlarged in the lower panels. Scale bars, $10 \mu \mathrm{m}$.

Figure 3. Co-inactivation of PXMP2 and PEX11B causes a small but significant decrease in the peroxisomal glutathione redox state in DD-myc-DAO FIp-In T-REx 293 cells. Control (CT), $\triangle \mathrm{PXMP} 2, \Delta \mathrm{PEX} 11 \mathrm{~B}$, or $\triangle \mathrm{PXMP} 2 \Delta \mathrm{PEX} 11 \mathrm{~B}$ (DKO) DD-myc-DAO Flp-In TREx 293 cells (A and B refer to distinct clones) were transfected with a plasmid encoding poroGFP2, a peroxisomal GSSG/GSH sensor, and cultured in regular MEM $\alpha$ medium. Two days later, the $400 / 480 \mathrm{~nm}$ fluorescence response ratios of the sensor were measured, and the values were presented as box plots. The response ratios were normalized to the average values of the corresponding control cell lines, which was set to 100 arbitrary units (AU): (A) single knockouts versus control cells; (B) DKO versus $\triangle$ PXMP2 (clone A) cells. The bottom and top of each box represent the 25 th and 75 th percentile values, respectively; the horizontal line inside each box represents the median; and the horizontal lines below and above each box denote the mean minus and plus one standard deviation, respectively. The number of randomly selected 
fields of view ( $2-5$ cells/field) is indicated below each box plot. The data from each knockout cell line were statistically compared with those from the corresponding control cells $(*, p<$ 0.01). A typical subcellular distribution pattern of po-roGFP2 is shown in Fig. S4.

Figure 4. PXMP2 is not essential for efficient $\mathrm{H}_{2} \mathrm{O}_{2}$ permeation across the peroxisomal membrane. Control (CT) and $\triangle \mathrm{PXMP} 2$ (clone A or B) DD-myc-DAO Flp-In T-REx 293 cells were transfected with a plasmid encoding cytosolic (c-) roGFP2-Orp1, a highly responsive $\mathrm{H}_{2} \mathrm{O}_{2}$ sensor, and cultured for 3 days in medium containing $1 \mu \mathrm{g} / \mathrm{ml}$ DOX and $500 \mathrm{nM}$ Shield1. Next, the cells were chased for one day in regular medium without DOX/Shield1. (A) Response ratios of c-roGFP2-Orp1 in function of time. The cells were incubated for one hour in DPBS containing $10 \mathrm{mM}$ 3-AT and subsequently incubated in the same buffer containing $10 \mathrm{mM} 3$ AT and $10 \mathrm{mM}$ D-Ala. The 400/480 nm fluorescence response ratios of c-roGFP2-Orp1 were measured at $0,5,15,30$, and 60 min after addition of D-Ala (for visual clarity, the curves obtained for clone A and clone B are slightly shifted horizontally). The response ratios were normalized to the average value of the " 0 min" conditions, which were set to 100 AU. Three independent experiments were performed (vertical bars represent standard deviations between these experiments). For each time point of each condition minimum 10 individual measurements were performed in at least 15 cells. (B) Immunoblot analysis of total cell lysates with antibodies specific for DAO or PEX14. The migration points of relevant molecular mass markers (expressed in $\mathrm{kDa}$ ) are shown on the left. *, degradation product of DD-myc-DAO.

Figure 5. Loss of PEX11B causes partial localization of peroxisomal proteins to mitochondria in DD-myc-DAO Flp-In T-REx 293 cells. Control (CT) or $\triangle \mathrm{PEX} 11 \mathrm{~B}$ (clone A or B) DD-myc-DAO Flp-In T-REx 293 cells were transfected or not with a plasmid encoding a PTS1 - or PTS2-tagged variant of EGFP (po-roGFP2 and PTS2-GFP, respectively). The cells were seeded on glass coverslips, cultured for three days in regular MEM $\alpha$ medium, and processed for direct or indirect fluorescence microscopy. Representative images are shown. The boxed areas in the left panels are enlarged in the right panels. The lower right panels show profile plots of fluorescence intensity (in percentage of pixel intensity; PPI) along the horizontal arrows. Vertical arrowheads and arrows indicate examples of mitochondria that stain positive or negative, respectively, for the peroxisomal protein under study. Scale bars, $10 \mu \mathrm{m}$.

Figure 6. Absence of PEX11B decreases the density of peroxisomes in DD-myc-DAO FlpIn T-REx 293 cells. Total cell homogenates (T) from control (CT) and $\triangle$ PEX11B (clone A) ( $\Delta 11 \mathrm{~B})$ DD-myc-DAO Flp-In T-REx 293 cells were fractionated by differential centrifugation 
to yield a $1500 \mathrm{x}$ g supernatant (Input, I) that was subsequently subjected to Nycodenz gradient centrifugation. (A) Densities of the different gradient fractions. (B) Equivalent volumes of the $\mathrm{T}$ and $\mathrm{I}$ fractions and equal volumes of each gradient fraction were processed for immunoblotting with antibodies directed against PEX13 (peroxisomes) and TOMM22 (mitochondria). The signals observed for I represent $8 \%$ of the amount present in the gradient fractions. The arrows indicate the fractions that are further analyzed in panel C. (C) Further immunoblot analysis of gradient fractions enriched in peroxisomes (CT: fraction $12 ; \Delta 11 \mathrm{~B}$ : fraction 14), mitochondria (CT and $\Delta 11 \mathrm{~B}$ : fraction 16), or cytosol (CT and $\Delta 11 \mathrm{~B}$ : fraction 22 ). Peroxisomes: PEX14 (PMP), ACAA1 (PTS2), HSD17B4 and CAT (PTS1); mitochondria: TOMM22; and cytosol: TUBA. The migration points of relevant molecular mass markers (expressed in $\mathrm{kDa}$ ) are shown on the left.

Figure 7. Mitochondrial po-roGFP2 is located in the intermembrane space in $\triangle \mathrm{PEX} 11 \mathrm{~B}$ DD-myc-DAO Flp-In T-REx 293 cells. $\triangle$ PEX11B (clone A or B) DD-myc-DAO Flp-In TREx 293 cells were transfected with a plasmid encoding peroxisomal (po-), mitochondrial (mt), or cytosolic (c-) roGFP2, a GSSG/GSH sensor, and cultured in MEM $\alpha$ medium. Two days later, the $400 / 480 \mathrm{~nm}$ fluorescence response ratios of the sensors were measured, and the values were presented as box plots (see capture to Fig. 3 for further explanation). The number of randomly selected fields of view (2-5 cells/field) is indicated below each box plot. For each cell line, the data from mitochondria-targeted po-roGFP2 were statistically compared with those from peroxisome-targeted po-roGFP2, mitochondria-targeted mt-roGFP2, and cytosolic roGFP2, and in all cases found to be significantly different $(*, p<0.01)$. The box plots of the data sets for roGFP2 variants correctly targeted to the appropriate cell compartment denote the same values as in Figs. 3 and S2. IMS, mitochondrial intermembrane space; AU, arbitrary units. 


\section{Legends to Supplementary Figures}

Figure S1. Expression and localization of DD-myc-DAO in control and PXMP2/PEX11B single or double knockout DD-myc-DAO Flp-In T-REx 293 cells. Control (CT), $\triangle \mathrm{PXMP} 2$ (clone B), $\triangle$ PEX11B (clone B), or $\triangle$ PXMP2 $\triangle$ PEX11B (clone B) DD-myc-DAO Flp-In T-REx 293 cells were first cultured for three days in the absence (no induction) or presence (induction + chase) of $1 \mu \mathrm{g} / \mathrm{ml}$ DOX and $500 \mathrm{nM}$ Shield1. Next, the cells were cultured for one additional day in medium lacking DOX and Shield1, and subsequently processed for fluorescence microscopy. The cells were stained with mouse anti-myc (myc) and rabbit anti-PEX14 (14) antibodies followed by anti-mouse TxRed and anti-rabbit Alexa 488-conjugated secondary antibodies. The nuclei were counterstained with DAPI. Representative images are shown. The boxed areas in the upper panels are enlarged in the lower panels. Scale bars, $10 \mu \mathrm{m}$.

Figure S2. Cytosolic and mitochondrial glutathione redox state are not detectably altered in PXMP2/PEX11B single or double knockout DD-myc-DAO Flp-In T-REx 293 cells. Control (CT), $\triangle$ PXMP2, $\triangle$ PEX11B, or $\triangle$ PXMP2 $\triangle$ PEX11B (DKO) DD-myc-DAO Flp-In TREx 293 cells (A and B refer to distinct clones) were transfected with a plasmid encoding (A, B) cytosolic (c-) or (C, D) mitochondrial (mt-) roGFP2 and cultured in regular MEM $\alpha$ medium. Two days later, the $400 / 480 \mathrm{~nm}$ fluorescence response ratios of the sensors were measured, and the values were presented as box plots (see capture to Fig. 3 for further explanation). The response ratios were normalized to the average values of the corresponding control cell lines, which was set to 100 arbitrary units (AU): $(\mathbf{A}, \mathbf{C})$ single knockouts versus control cells; $(\mathbf{B}, \mathbf{D})$ DKO versus $\triangle \mathrm{PXMP} 2$ (clone A) cells. The data from each knockout cell line were statistically compared with those from the corresponding control cells, but no statistical differences $(p<$ 0.01) were observed. Typical subcellular distribution patterns of c-roGFP2 and mt-roGFP2 are depicted in Fig. S4.

Figure S3. Cytosolic and mitochondrial $\mathrm{H}_{2} \mathrm{O}_{2}$ levels are not detectably altered in PXMP2/PEX11B single or double knockout DD-myc-DAO Flp-In T-REx 293 cells. Control (CT), $\triangle \mathrm{PXMP} 2, \Delta \mathrm{PEX} 11 \mathrm{~B}$, or $\triangle \mathrm{PXMP} 2 \Delta \mathrm{PEX} 11 \mathrm{~B}$ (DKO) DD-myc-DAO Flp-In TREx 293 cells (A and B refer to distinct clones) were transfected with a plasmid encoding (A, B) cytosolic (c-) or (C, D) mitochondrial (mt-) roGFP2-Orp1 and cultured in regular MEM $\alpha$ medium. Two days later, the 400/480 $\mathrm{nm}$ fluorescence response ratios of the sensors were measured, and the values were presented as box plots (see capture to Fig. 3 for further 
explanation). The response ratios were normalized to the average values of the corresponding control cell lines, which was set to 100 arbitrary units (AU): (A, C) single knockouts versus control cells; (B, D) DKO versus $\triangle \mathrm{PXMP2}$ (clone A) cells. The data from each knockout cell line were statistically compared with those from the corresponding control cells, but no statistical differences $(\mathrm{p}<0.01)$ were observed. Typical subcellular distribution patterns of $\mathrm{c}-$ roGFP2-Orp1 and mt-roGFP2-Orp1 are depicted in Fig. S4.

Figure S4. Typical distribution patterns of the employed roGFP2 and roGFP2-Orp1 sensors in DD-myc-DAO Flp-In T-REx 293 cells. DD-myc-DAO Flp-In T-REx 293 cells were transiently transfected with a plasmid encoding peroxisomal (po-), cytosolic (c-), or mitochondrial (mt-) roGFP2 or roGFP2-Orp1, and subsequently cultured in regular MEM $\alpha$ medium. Two days later, the cells were processed for direct fluorescence microscopy. Representative images are shown. Scale bars: $10 \mu \mathrm{m}$.

Figure S5. PEX11B is not essential for efficient $\mathrm{H}_{2} \mathrm{O}_{2}$ permeation across the peroxisomal membrane. Control (CT) and $\triangle \mathrm{PEX} 11 \mathrm{~B}$ (clone A or B) DD-myc-DAO Flp-In T-REx 293 cells were transfected with a plasmid encoding cytosolic (c-) roGFP2-Orp1, a highly responsive $\mathrm{H}_{2} \mathrm{O}_{2}$ sensor, and cultured for 2 days in medium containing $1 \mu \mathrm{g} / \mathrm{ml}$ DOX and $500 \mathrm{nM}$ Shield 1 . Next, the cells were chased for one day in regular medium without DOX/Shield1. (A) Response ratios of c-roGFP2-Orp1 in function of time. The cells were incubated for one hour in DPBS containing $10 \mathrm{mM}$ 3-AT and subsequently incubated in the same buffer containing $10 \mathrm{mM} 3$ AT and $10 \mathrm{mM}$ D-Ala. The 400/480 nm fluorescence response ratios of c-roGFP2-Orp1 were measured at $0,5,15,30$, and 60 min after addition of D-Ala (for visual clarity, the curves obtained for clone A and clone B are slightly shifted horizontally). The response ratios were normalized to the average value of the " 0 min" conditions, which were set to 100 AU. Three independent experiments were performed (vertical bars represent standard deviations between these experiments). For each time point of each condition minimum 10 individual measurements were performed in at least 14 cells. (B) Immunoblot analysis of total cell lysates with antibodies specific for DAO or PEX14. The migration points of relevant molecular mass markers (expressed in $\mathrm{kDa}$ ) are shown on the left. *, degradation product of DD-myc-DAO.

Figure S6. The efficiency of $\mathrm{H}_{2} \mathrm{O}_{2}$ permeation across the peroxisomal membrane is not affected in cells lacking PXMP2 and PEX11B. $\triangle \mathrm{PXMP} 2$ (clone $\mathrm{A}$ ) or $\triangle \mathrm{PXMP} 2 \triangle \mathrm{PEX} 11 \mathrm{~B}$ (DKO, clone A or B) DD-myc-DAO Flp-In T-REx 293 cells were transfected with a plasmid encoding cytosolic (c-) roGFP2-Orp1, a highly responsive $\mathrm{H}_{2} \mathrm{O}_{2}$ sensor, and cultured as 
described for the $\triangle \mathrm{PXMP} 2$ cells in Fig. 4. (A) Response ratios of c-roGFP2-Orp1 in function of time. The cells were incubated for one hour in DPBS containing $10 \mathrm{mM} 3-\mathrm{AT}$ and subsequently incubated in the same buffer containing $10 \mathrm{mM} \mathrm{3-AT}$ and $10 \mathrm{mM}$ D-Ala. The $400 / 480 \mathrm{~nm}$ fluorescence response ratios of c-roGFP2-Orp1 were measured at 0, 5, 15, 30 and 60 min after addition of D-Ala (for visual clarity, the curves obtained for the DKO cell lines are slightly shifted horizontally). The response ratios were normalized to the average value of the "0 min" conditions, which were set to 100 AU. Four independent experiments were performed (vertical bars represent standard deviations between these experiments). For each time point of each condition minimum 10 individual measurements were performed in at least 15 cells. (B) Immunoblot analysis of total cell lysates with antibodies specific for DAO or PEX14. The migration points of relevant molecular mass markers (expressed in $\mathrm{kDa}$ ) are shown on the left. *, degradation product of DD-myc-DAO.

Figure S7. Loss of PEX11B causes partial localization of peroxisomal proteins to mitochondria in $\triangle$ PXMP2 DD-myc-DAO Flp-In T-REx 293 cells. $\triangle$ PXMP2 (clone A) (CT) or $\triangle \mathrm{PXMP} 2 \Delta \mathrm{PEX} 11 \mathrm{~B}$ (clone A or B) DD-myc-DAO Flp-In T-REx 293 cells were transfected or not with a plasmid encoding a PTS1- or PTS2-tagged variant of EGFP (po-roGFP2 and PTS2-GFP, respectively). The cells were seeded on glass coverslips, cultured for three days in regular MEM $\alpha$ medium, and processed for direct or indirect fluorescence microscopy. Representative images are shown. The boxed areas in the left panels are enlarged in the right panels. The lower right panels show profile plots of fluorescence intensity (in percentage of pixel intensity; PPI) along the horizontal arrows. Vertical arrowheads and arrows indicate examples of mitochondria that stain positive or negative, respectively, for the peroxisomal protein under study. Scale bars, $10 \mu \mathrm{m}$.

Figure S8. Loss of PEX11B causes partial localization of peroxisomal proteins to mitochondria in HepG2 cells. Control (CT) or $\triangle$ PEX11B (clone A or B) HepG2 cells were transfected or not with a plasmid encoding a PTS1- or PTS2-tagged variant of EGFP (poroGFP2 and PTS2-GFP, respectively). The cells were seeded on glass coverslips, cultured for three days in regular MEM $\alpha$ medium, and processed for direct or indirect fluorescence microscopy. Representative images are shown. The boxed areas in the left panels are enlarged in the right panels. The lower right panels show profile plots of fluorescence intensity (in percentage of pixel intensity; PPI) along the horizontal arrows. Vertical arrowheads and arrows 
indicate examples of mitochondria that stain positive or negative, respectively, for the peroxisomal protein under study. Scale bars, $10 \mu \mathrm{m}$.

Figure S9. Immunoblot validation of the CRISPR-Cas9 HepG2 cell lines. Total cell lysates from control (CT) or $\triangle \mathrm{PEX} 11 \mathrm{~B}$ (clone A or B) HepG2 cells, all containing equal amounts of protein, were subjected to sodium carbonate treatment to separate soluble and peripheral proteins from integral membrane proteins. The carbonate-insoluble fractions were subsequently processed for SDS-PAGE, Western blotting, and immunoblot analysis with an antiserum directed against PEX11B.

Figure S10. Mitochondrial po-roGFP2 is located in the intermembrane space in $\triangle$ PXMP2 $\triangle$ PEX11B DD-myc-DAO Flp-In T-REx 293 cells. $\triangle$ PXMP2 $\triangle$ PEX11B (DKO; clone A or B) DD-myc-DAO Flp-In T-REx 293 cells were transfected with a plasmid encoding peroxisomal (po-), mitochondrial (mt-), or cytosolic (c-) roGFP2, a GSSG/GSH sensor, and cultured in MEM $\alpha$ medium. Two days later, the 400/480 nm fluorescence response ratios of the sensors were measured, and the values were presented as box plots (see capture to Fig. 3 for further explanation). The number of randomly selected fields of view ( $2-5$ cells/field) is indicated below each box plot. For each cell line, the data from mitochondria-targeted poroGFP2 were statistically compared with those from peroxisome-targeted po-roGFP2, mitochondria-targeted mt-roGFP2, and cytosolic roGFP2, and in all cases found to be significantly different $(*, p<0.01)$. The box plots of the data sets for roGFP2 variants correctly targeted to the appropriate cell compartment denote the same values as in Figs. 3 and S2. IMS, mitochondrial intermembrane space.

Figure S11. PEX5 co-enriches with plasma membrane-targeted PEX14 in DD-myc-DAO Flp-In T-REx 293 cells. DD-myc-DAO Flp-In T-REx 293 cells were co-transfected with plasmids encoding HsPEX14-EGFP or HsPEX5-mCherry, in combination (+) or not (-) with a plasmid coding for a high-affinity plasma membrane-targeted anti-EGFP nanobody $\left(\mathrm{GFP}_{\mathrm{Nb}^{-}}\right.$ PM). The cells were subsequently cultured in complete MEM $\alpha$ medium and, one day later, they were analyzed by fluorescence microscopy. Representative localization patterns are shown. The boxed areas in the left panels are enlarged in the right panels. The lower right panels show profile plots of fluorescence intensity (in percentage of pixel intensity; PPI) along the horizontal arrows (green line, HsPEX14-EGFP; red line, HsPEX5-mCherry). Scale bar: $10 \mu \mathrm{m}$. 
Figure S12. Overexpression of PEX14 in $\triangle$ PEX11B DD-myc-DAO FIp-In T-REx 293 cells promotes the recruitment of PEX5 to mitochondria. $\triangle$ PEX11B (clone A) DD-myc-DAO Flp-In T-REx 293 cells were (co-)transfected with (a) plasmid(s) coding for PEX5-EGFP in combination $(+)$ or not (-) with a plasmid encoding PEX14 (in a plasmid ratio of 1:10). The cells were seeded in FluoroDish cell culture dishes, cultured for two days in regular MEM $\alpha$ medium, and processed for direct fluorescence microscopy. Representative images are shown. The boxed areas in the left panels are enlarged in the right panels. The lower right panels show profile plots of fluorescence intensity (in percentage of pixel intensity; PPI) along the horizontal arrows. Vertical arrows and arrowheads indicate examples of mitochondria that stain negative or positive, respectively, for PEX5-EGFP. Scale bars, $10 \mu \mathrm{m}$.

Figure S13. Relative mRNA expression levels of PEX11A and PEX11B in control and APEX11B DD-myc-DAO Flp-In T-REx 293 cells. Relative mRNA levels of PEX11A (11A) and PEX11B (11B) in control (CT) and $\triangle$ PEX11B ( $\triangle 11 \mathrm{~B})$ DD-myc-DAO Flp-In T-REx 293 cells were determined with RT-qPCR. Results are shown as mean $\pm \operatorname{standard~deviation~}(n=3)$. Mean values for $11 \mathrm{~B}$ were set to 1.00 and values for $11 \mathrm{~A}$ are expressed relative to $11 \mathrm{~B}$. The transcript levels were corrected for the geometric mean of the housekeeping genes PPIB, RPLP0, and ACTB. 


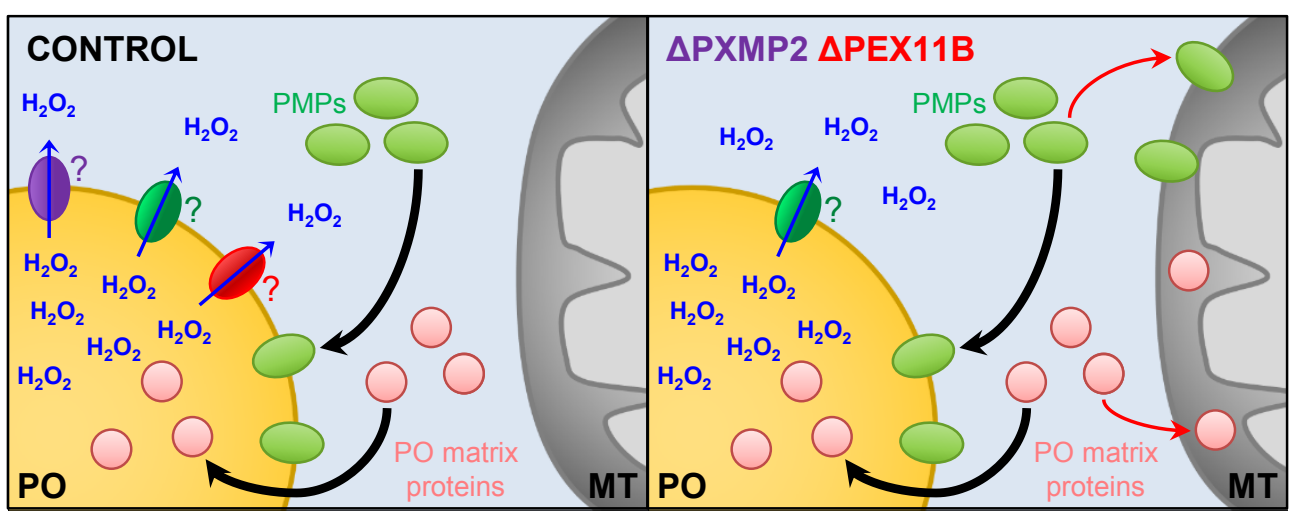


Figure 1

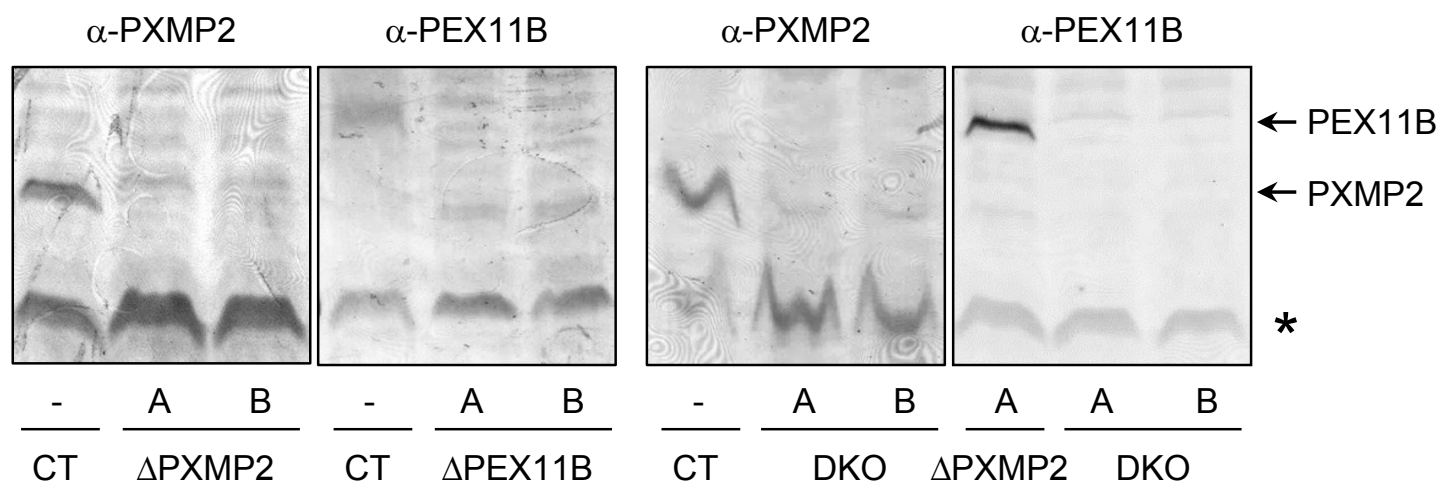




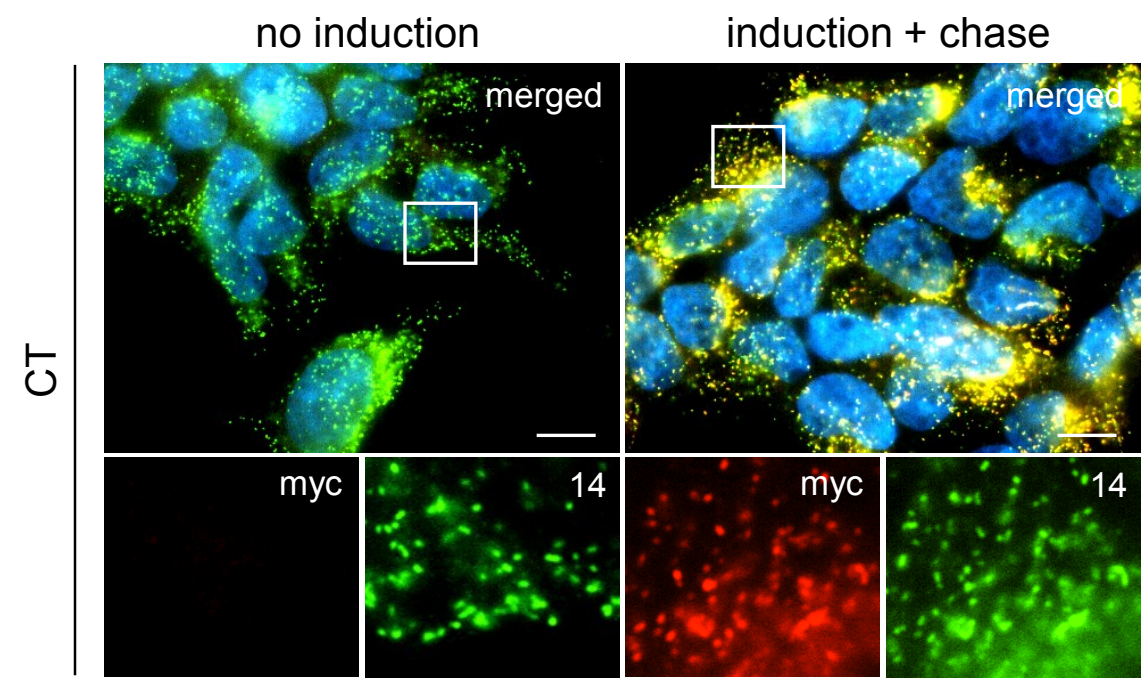

Figure 2
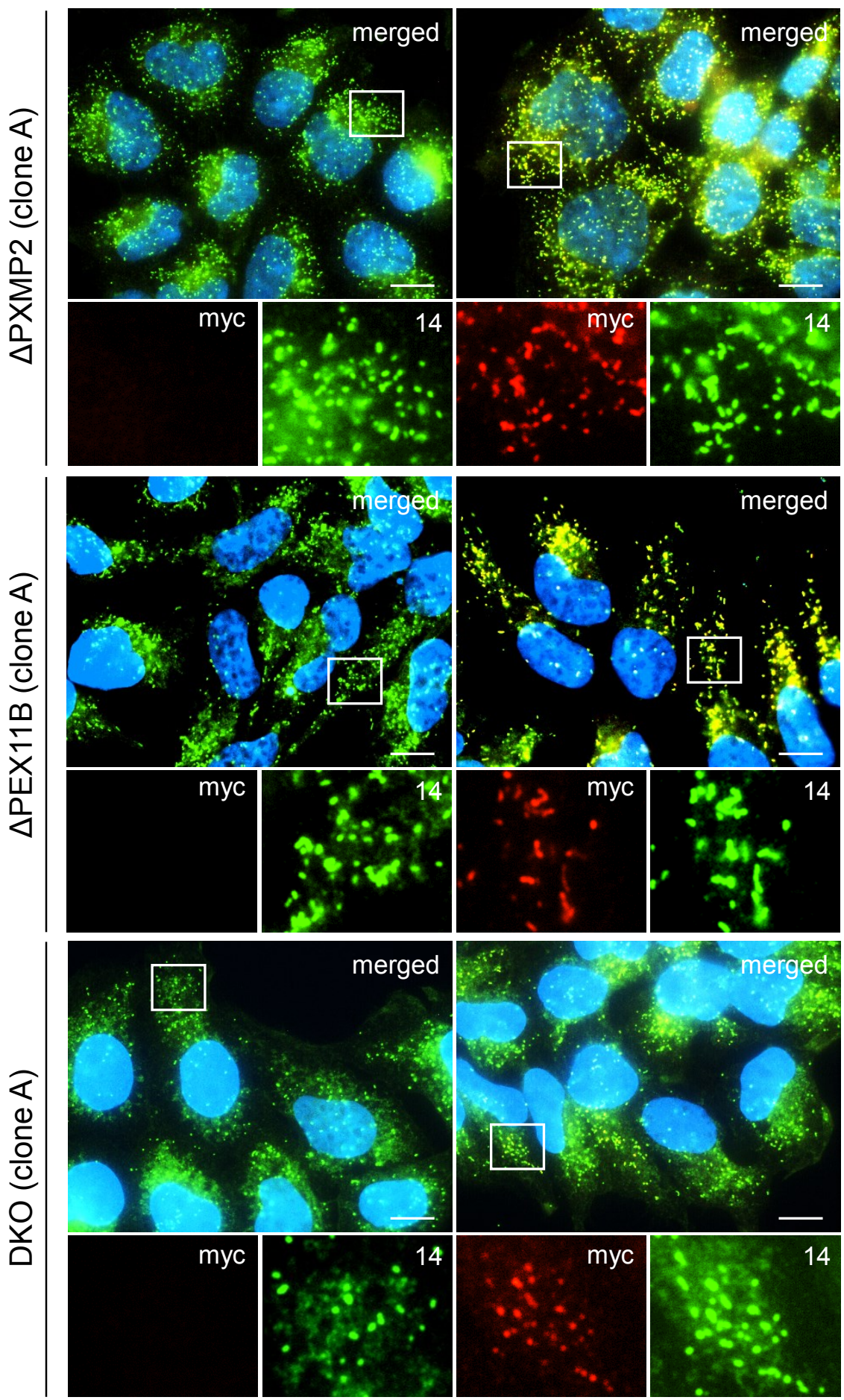
Figure 3

A

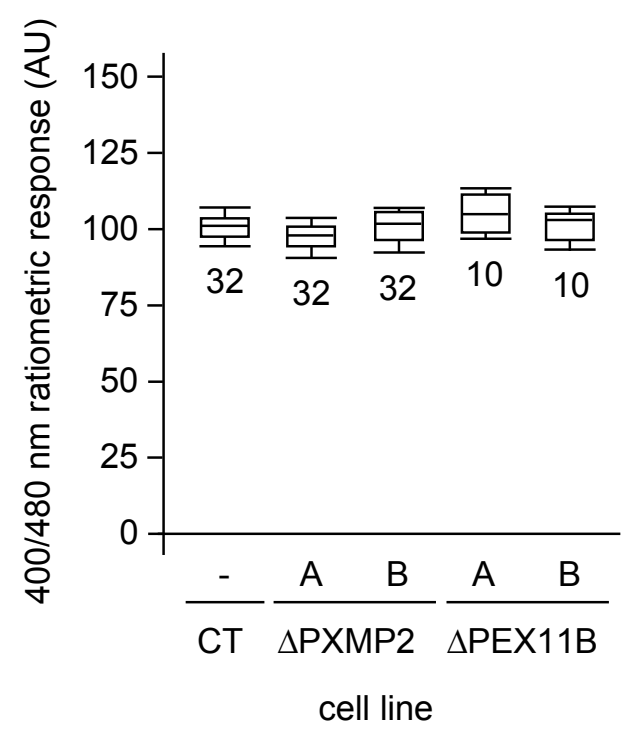

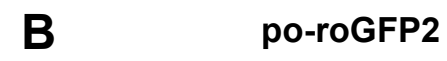

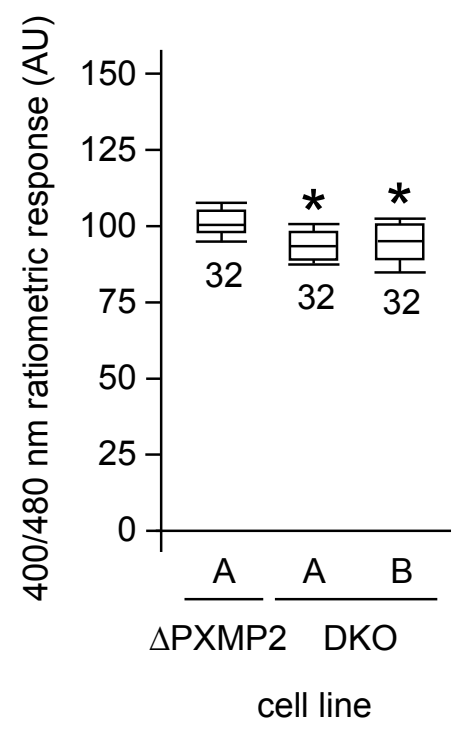


Figure 4

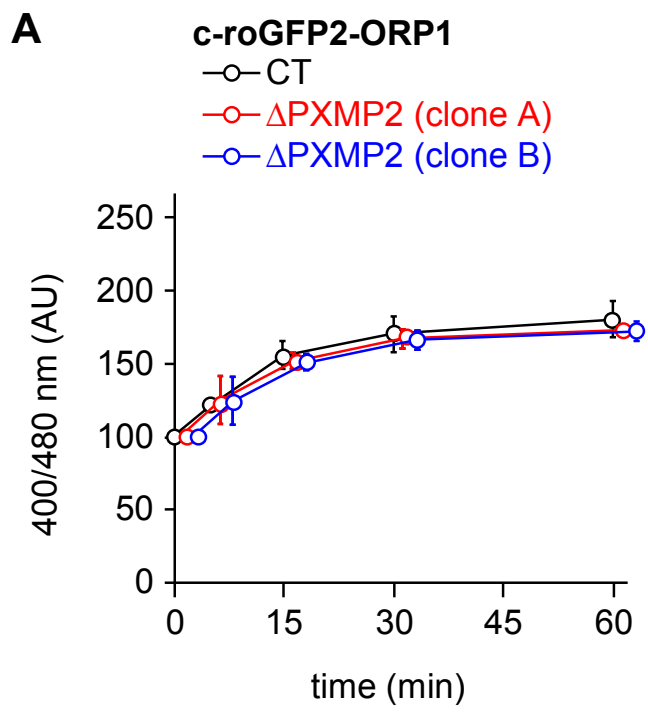

B

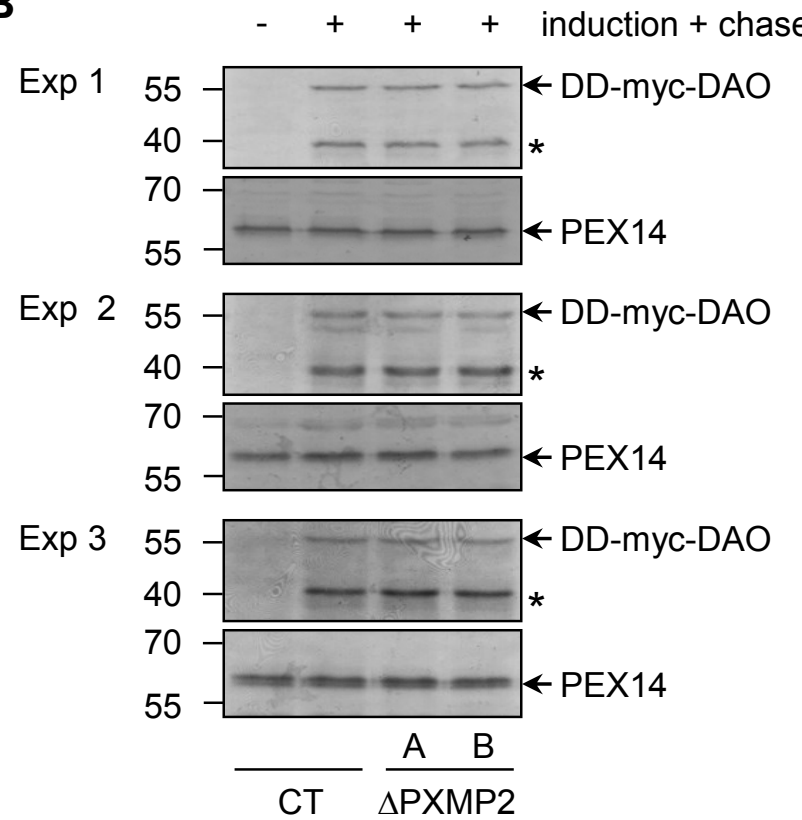


Figure 6

A

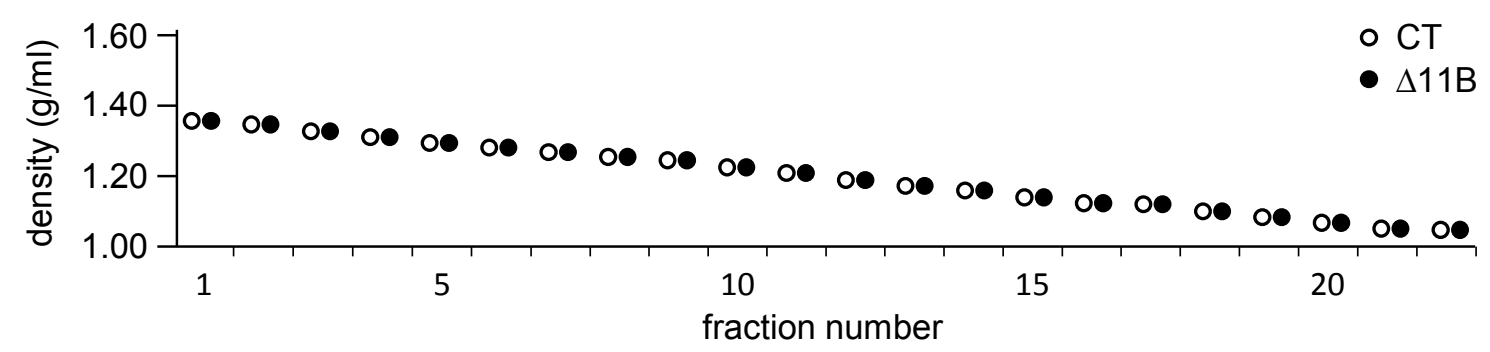

B
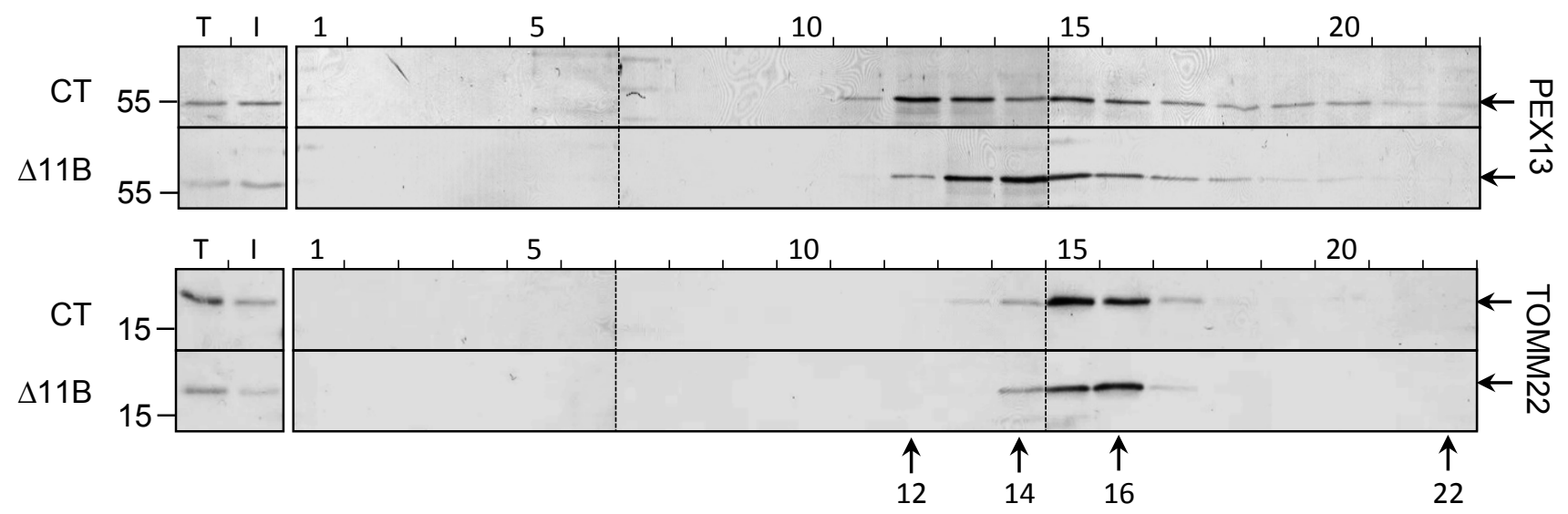

C
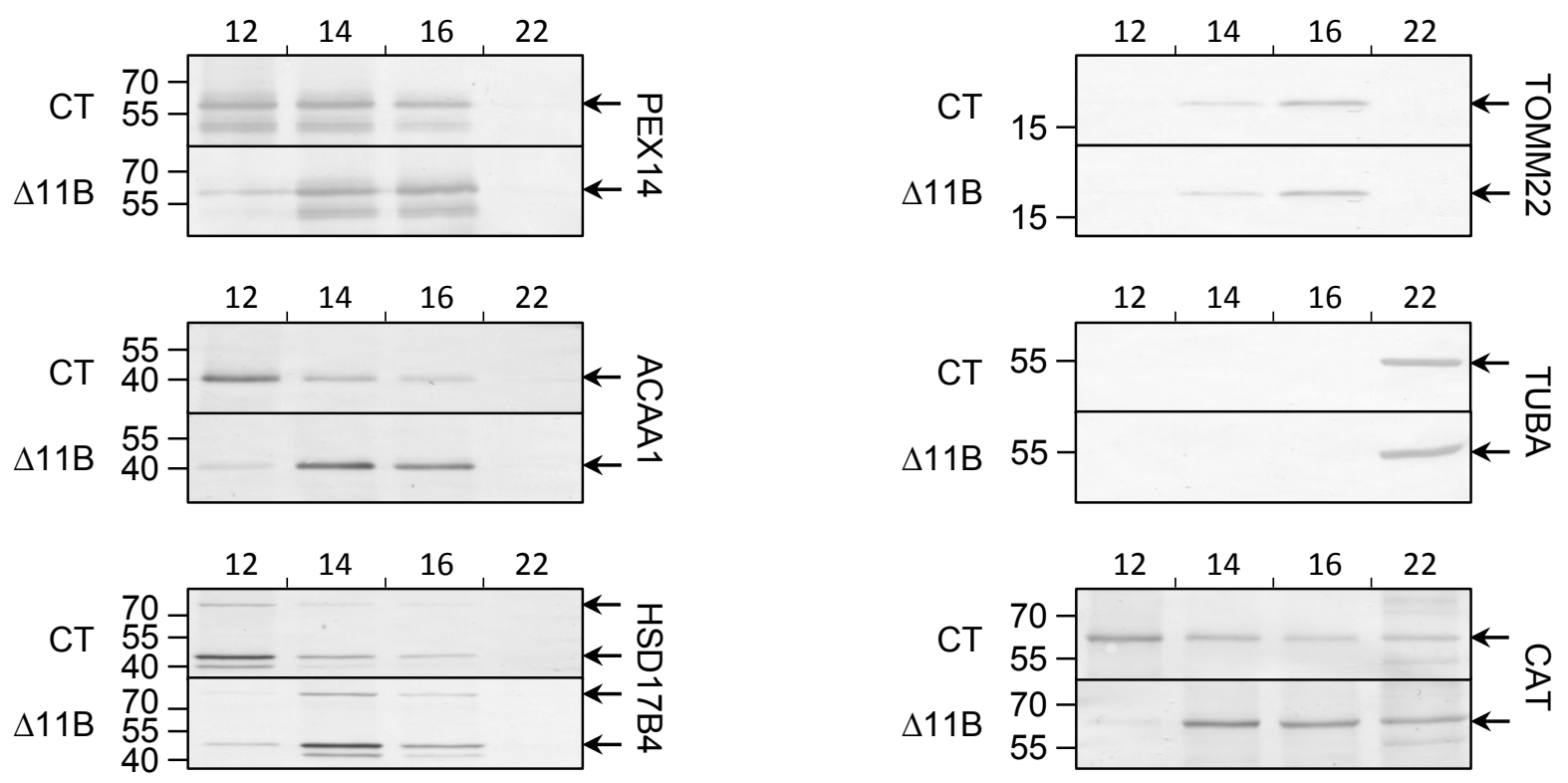
Figure 7

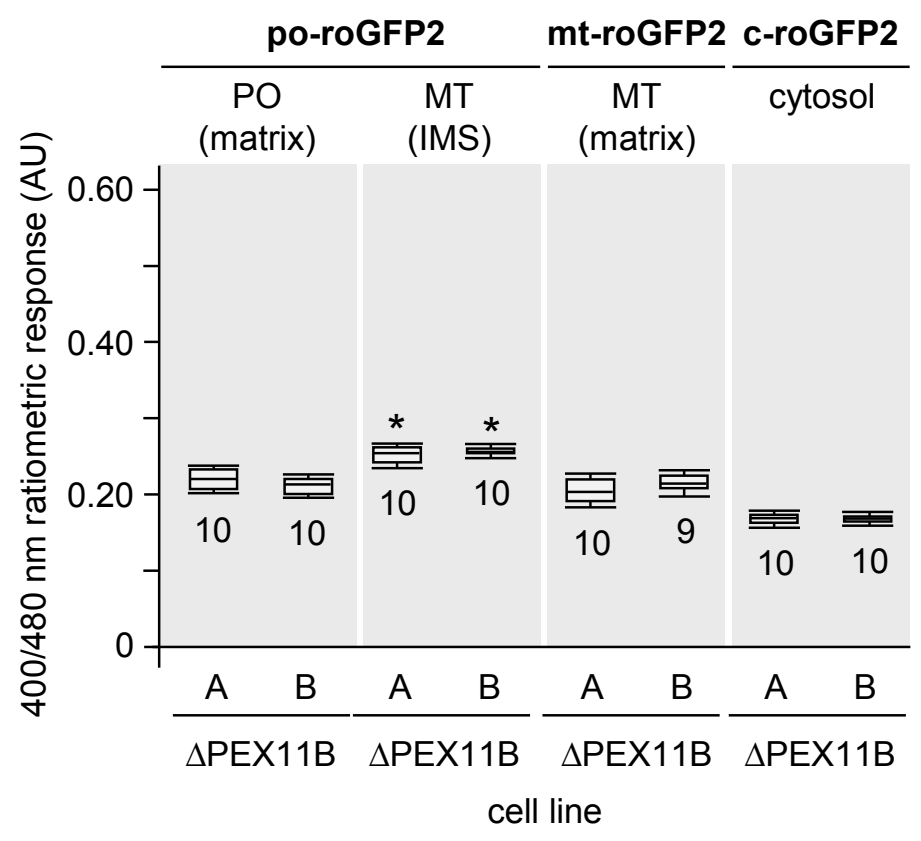



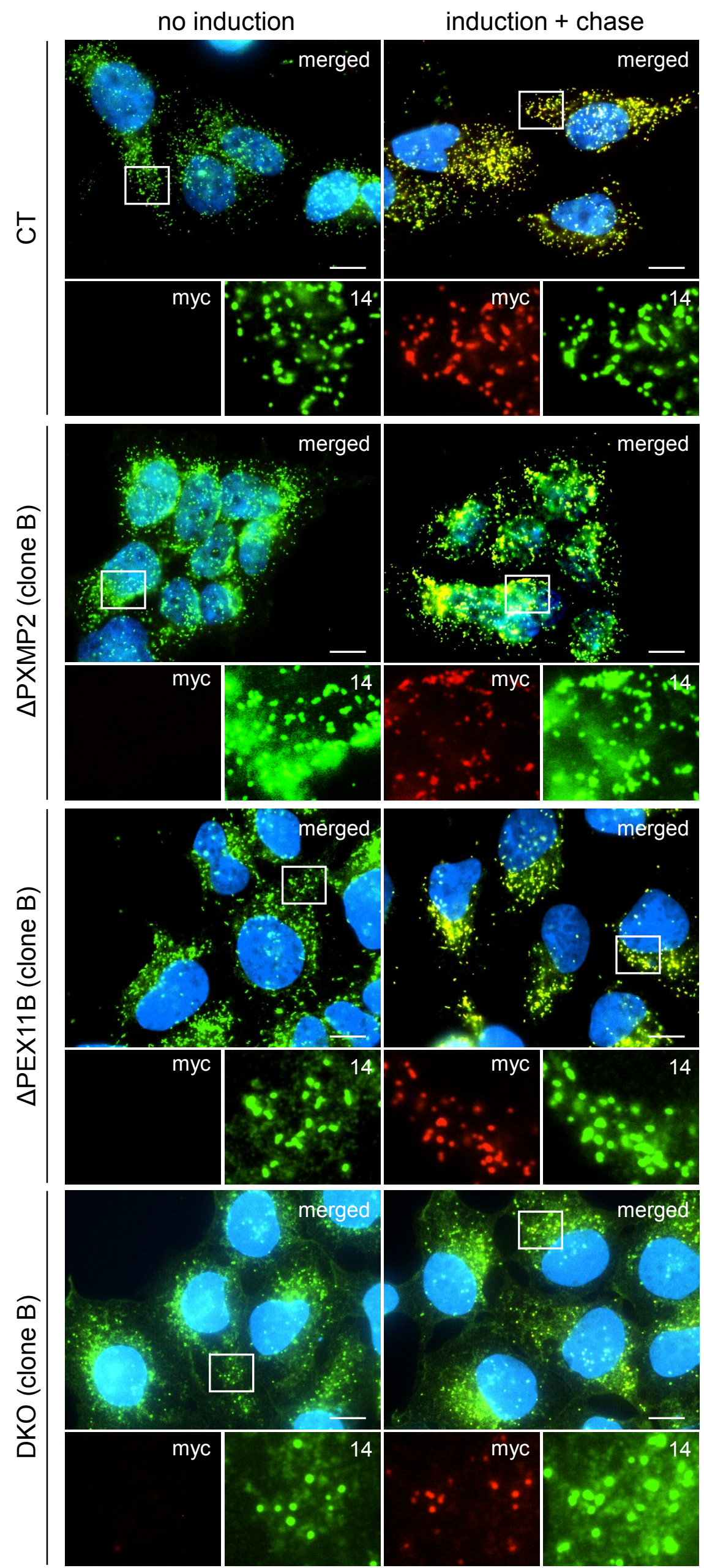
A

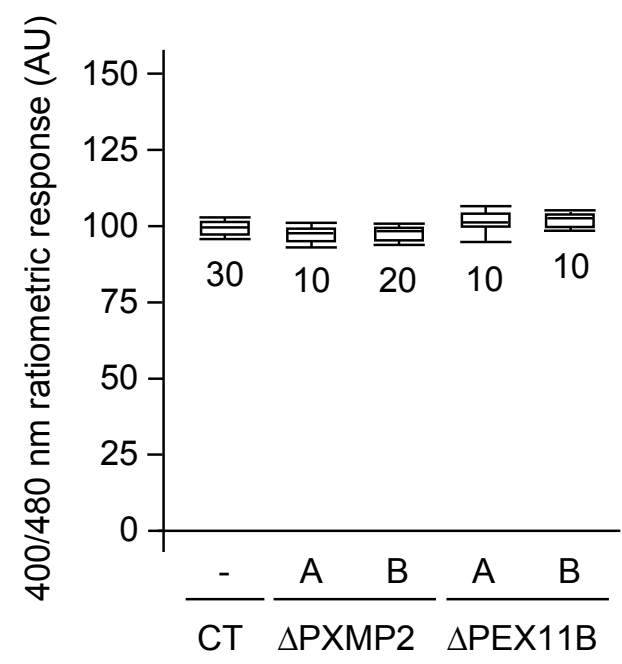

cell line

C

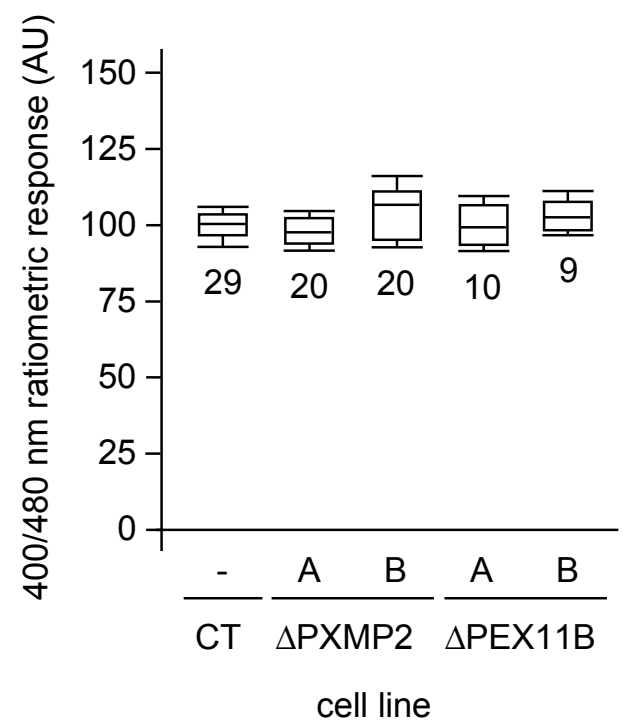

B

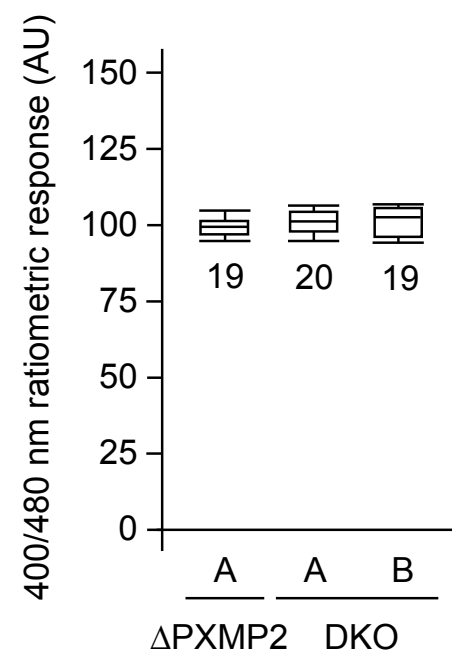

cell line

D mt-roGFP2

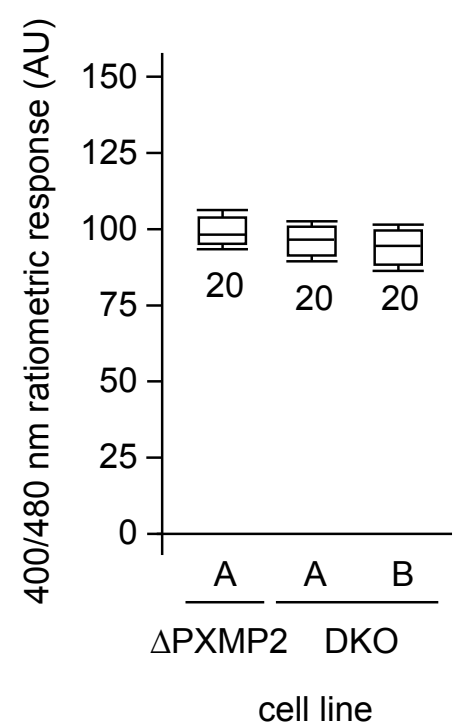


A

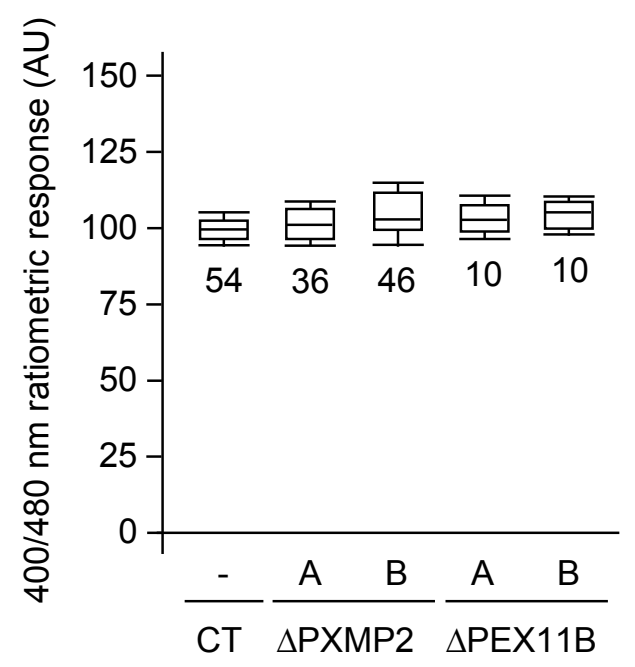

cell line

C

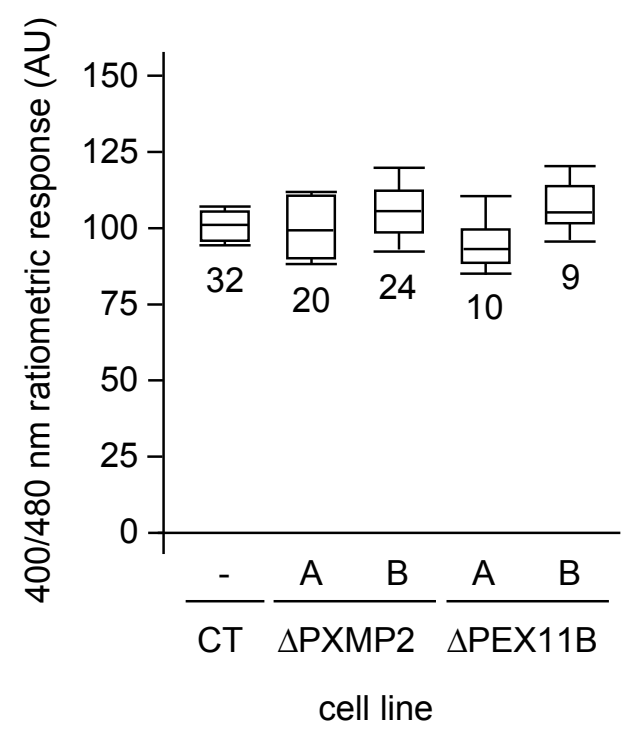

B c-roGFP2-Orp1

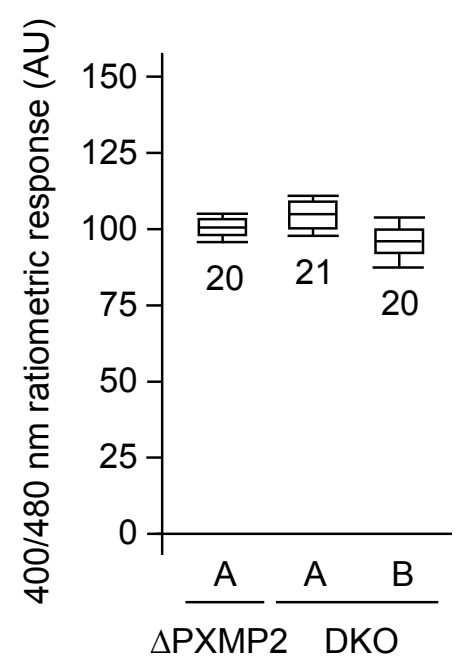

cell line

D mt-roGFP2-Orp1

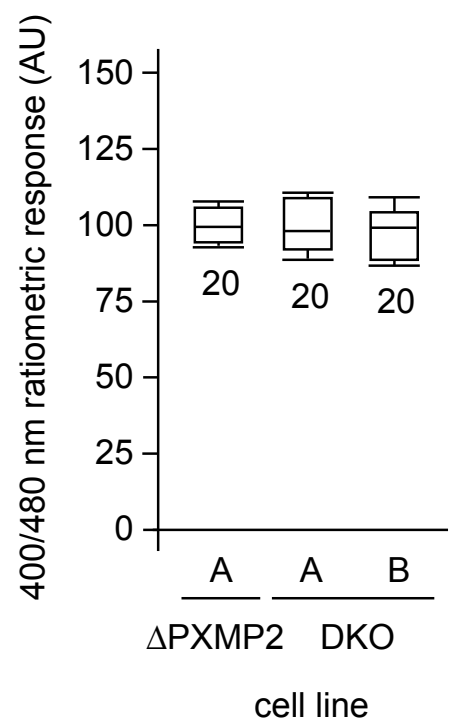


Figure S4

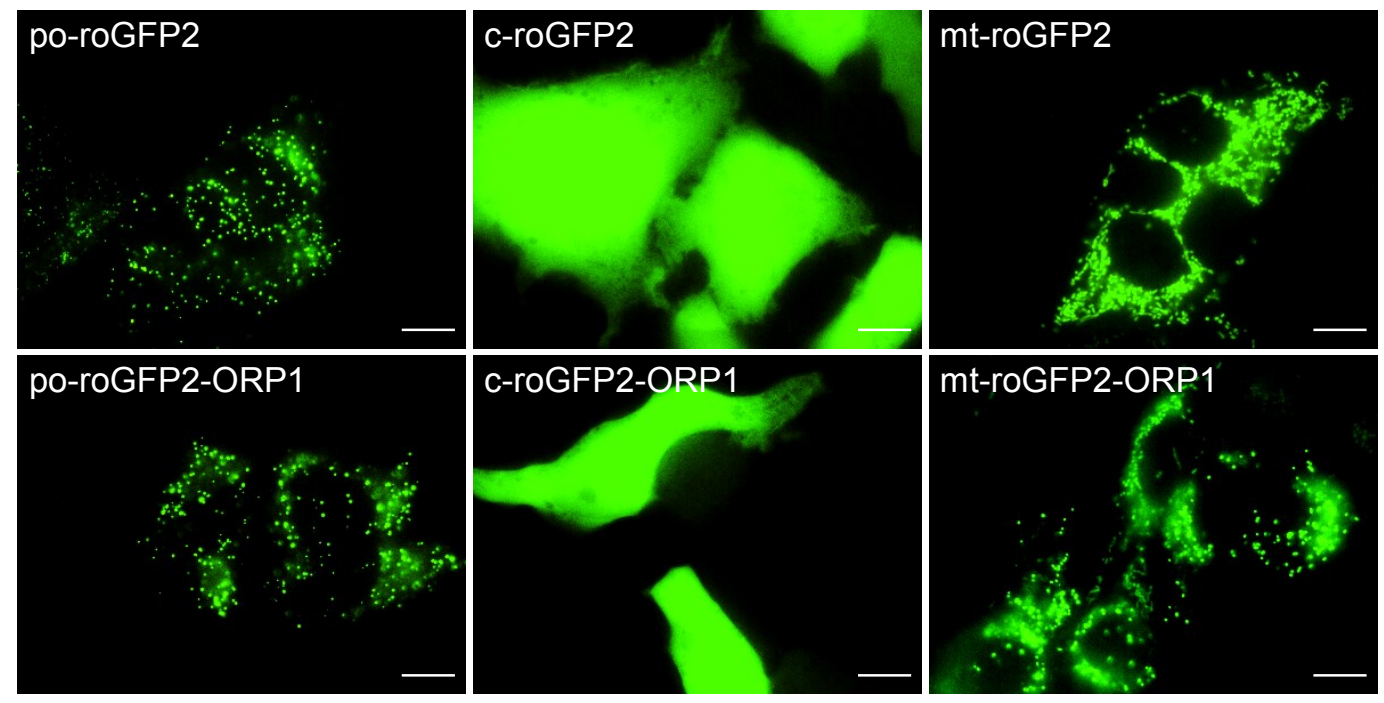


Figure S5

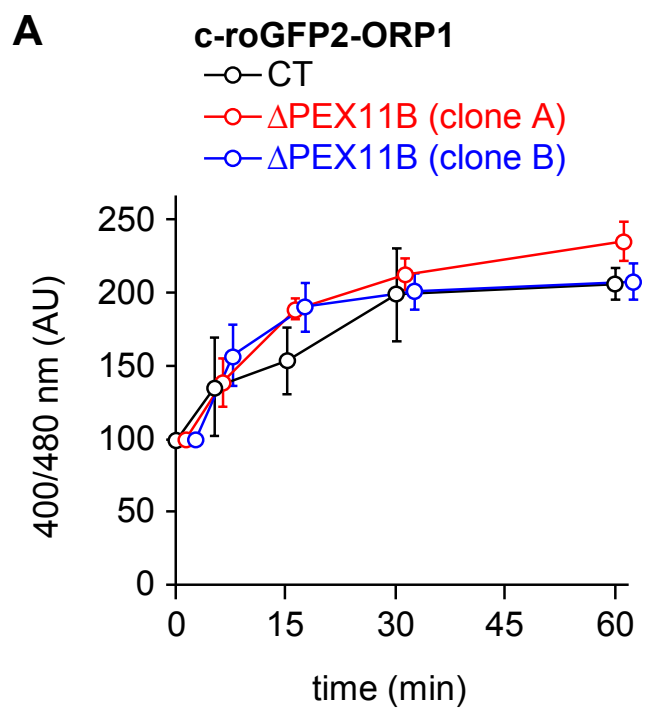

B

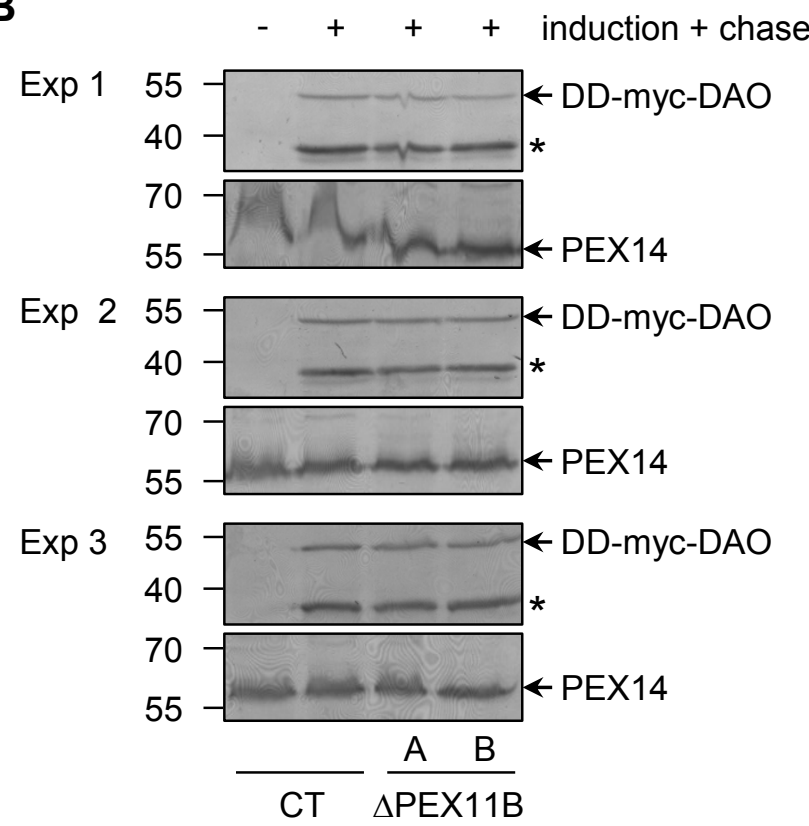


Figure S6
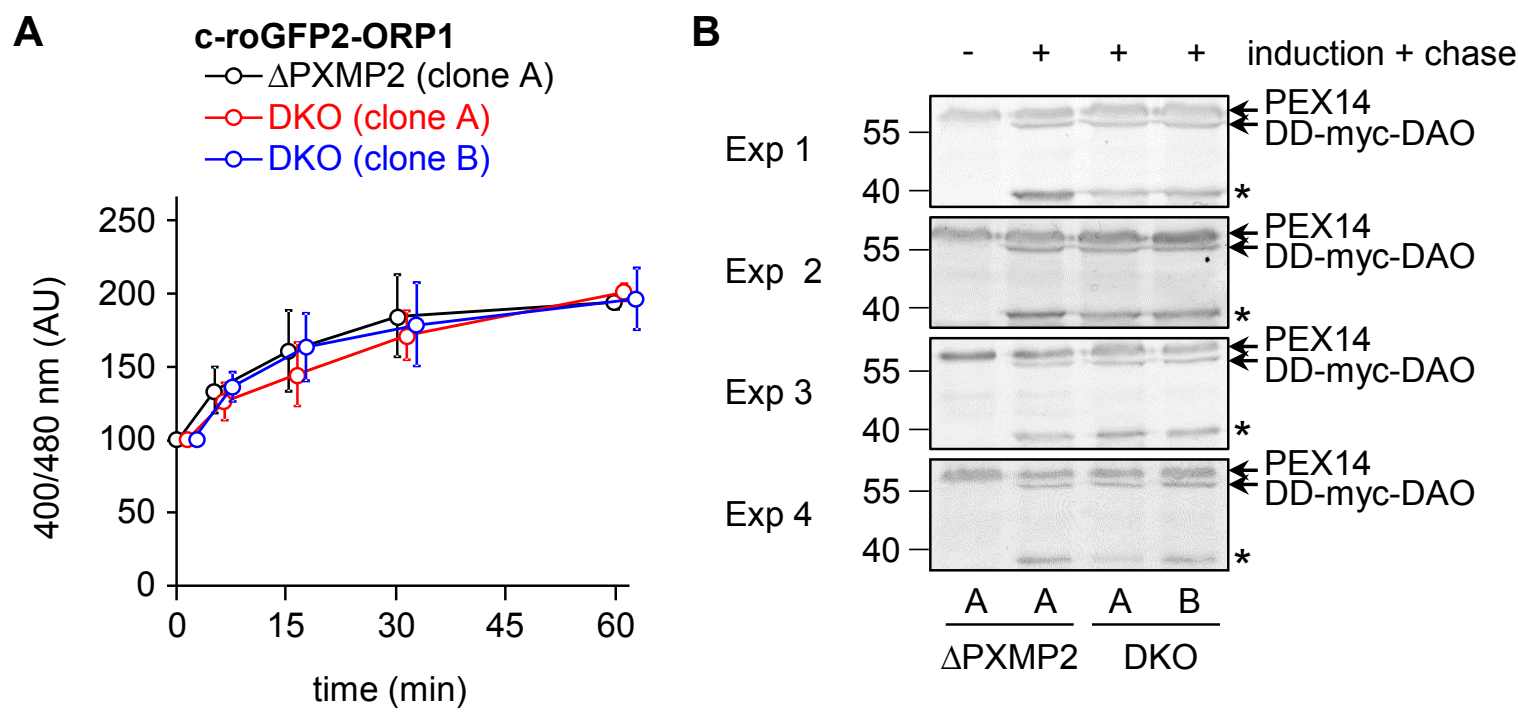
Figure S7
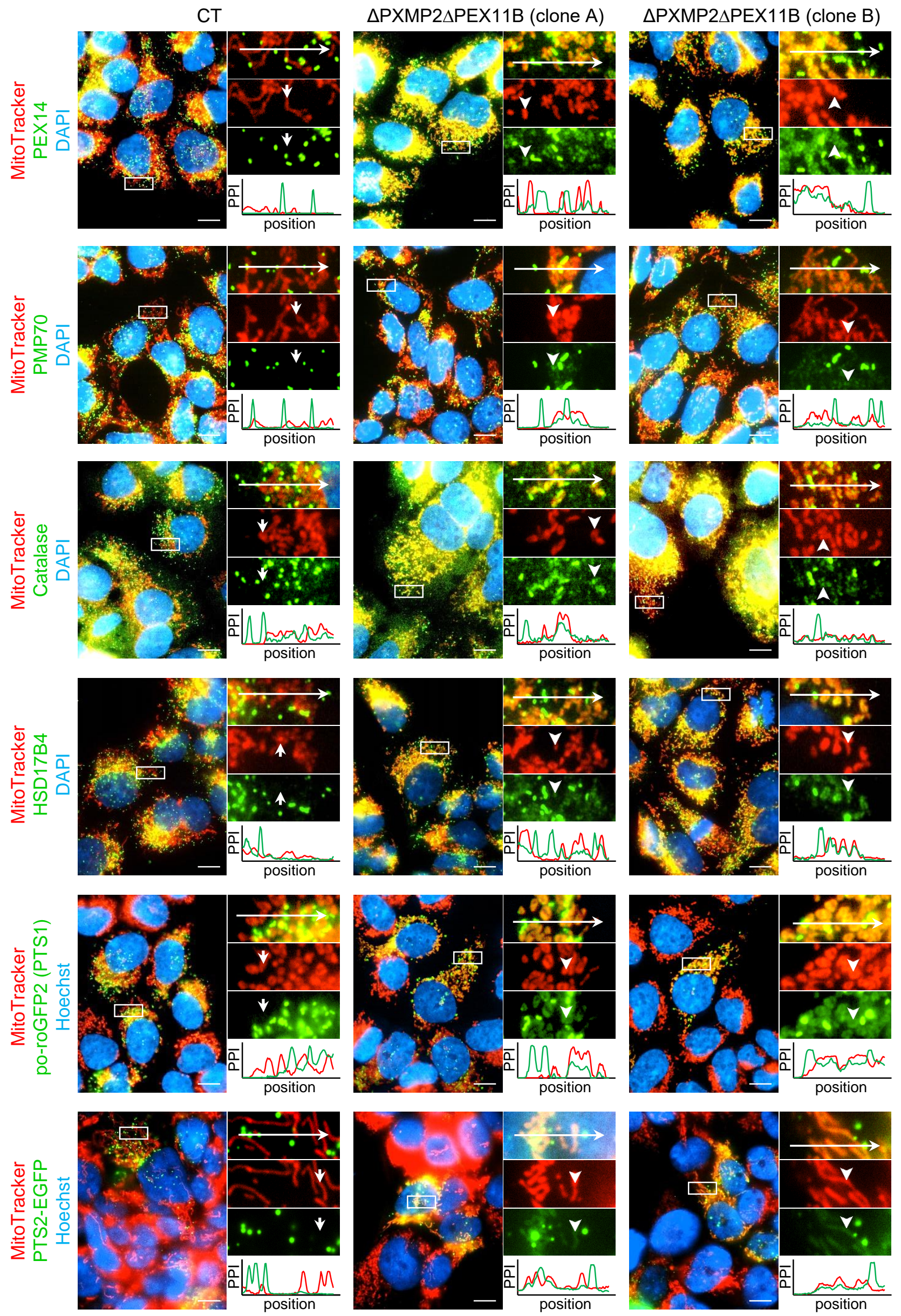
Figure S8
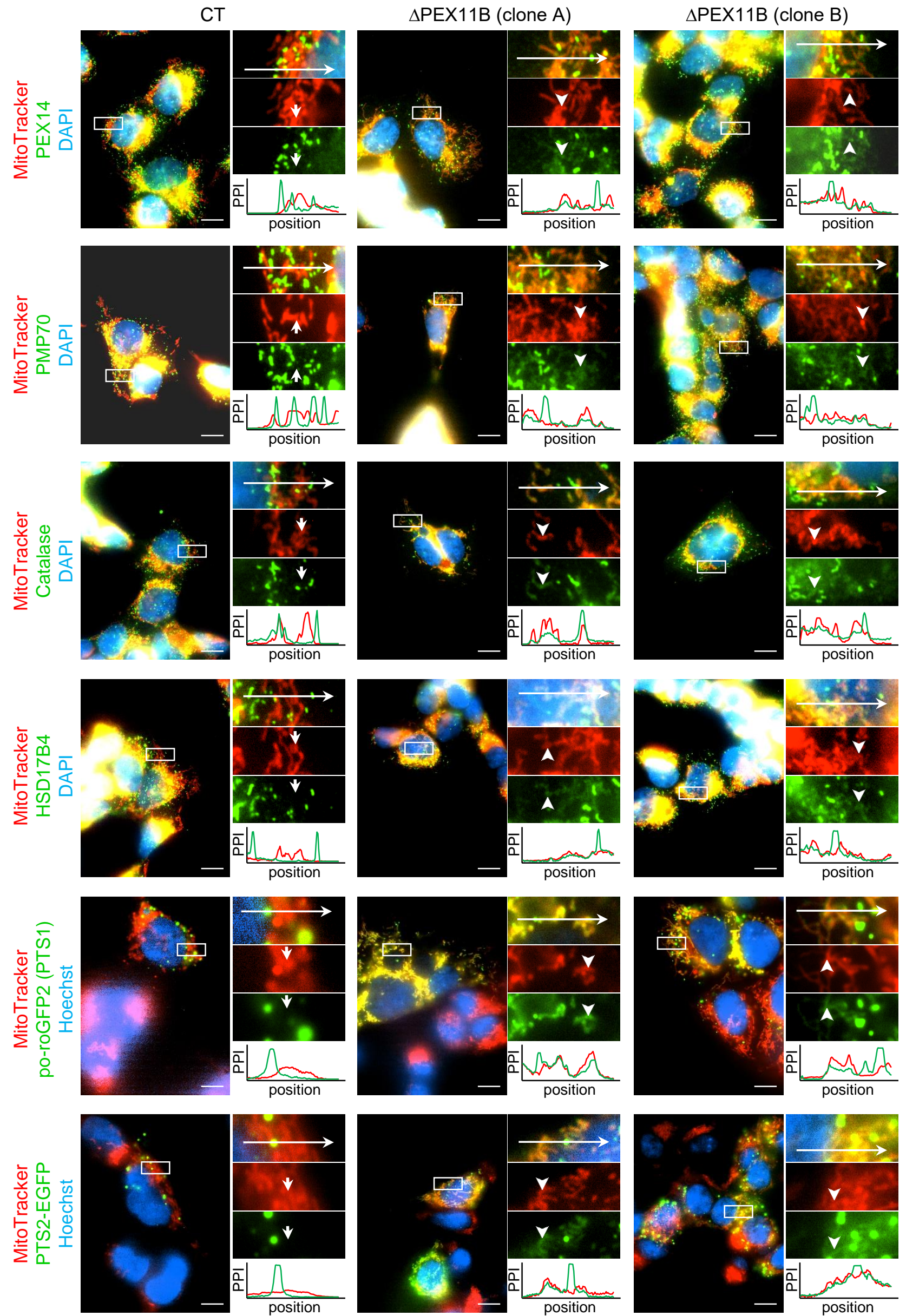
Fig. $\mathbf{S 9}$

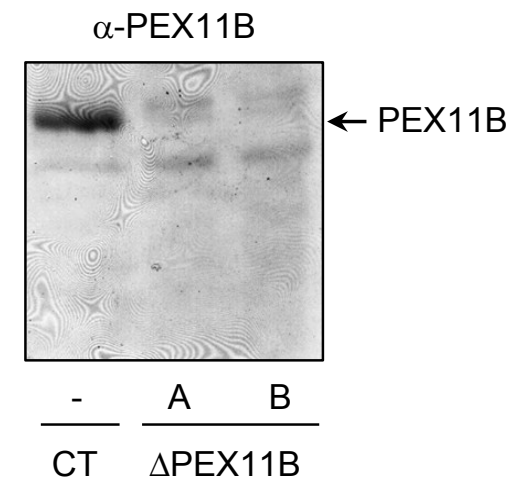




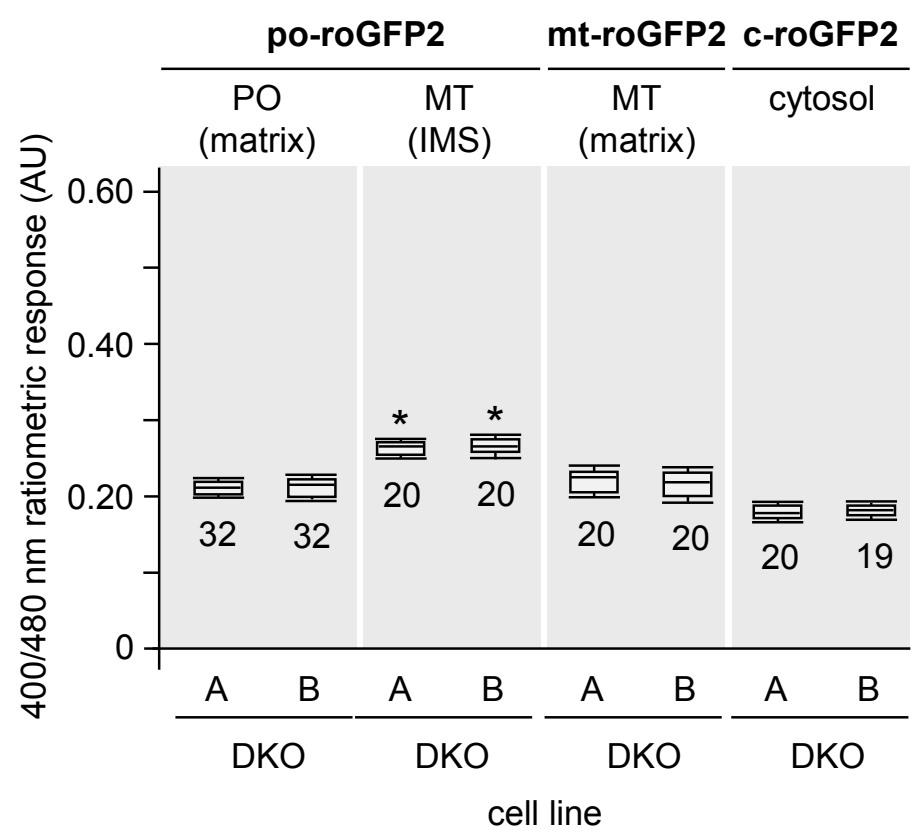


Figure S11

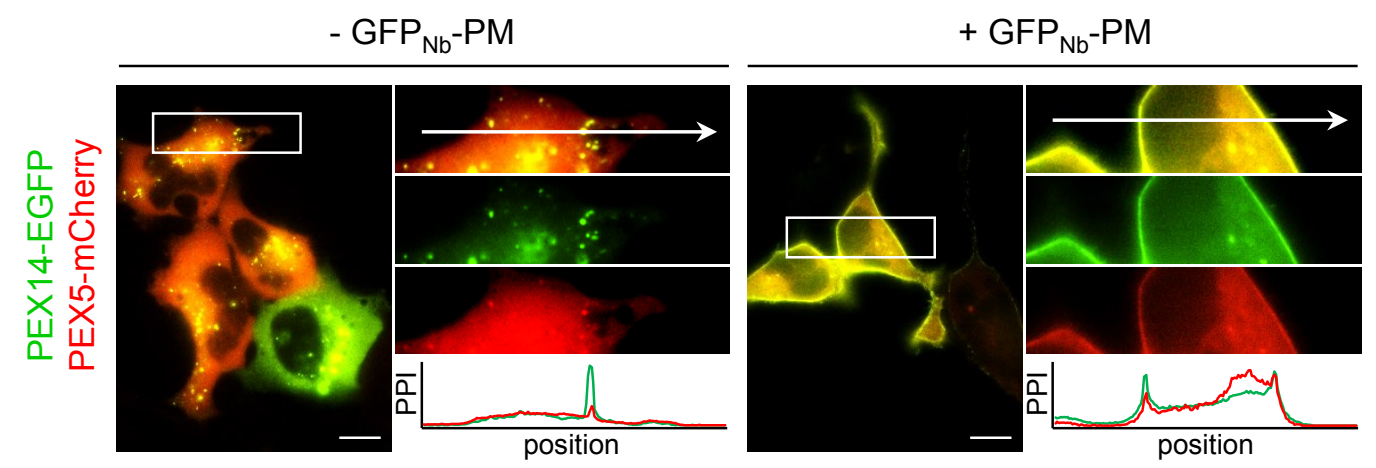


Figure S12

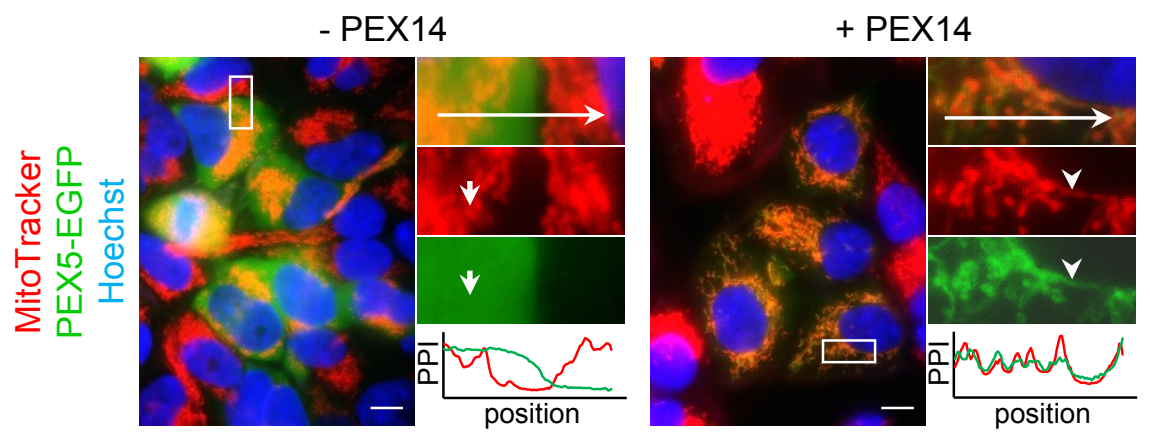


Figure S13

A

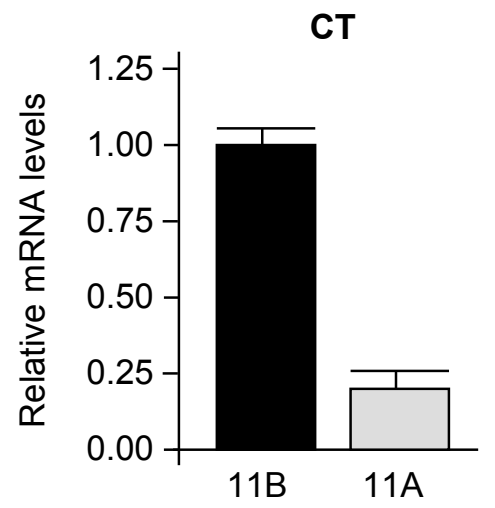

B

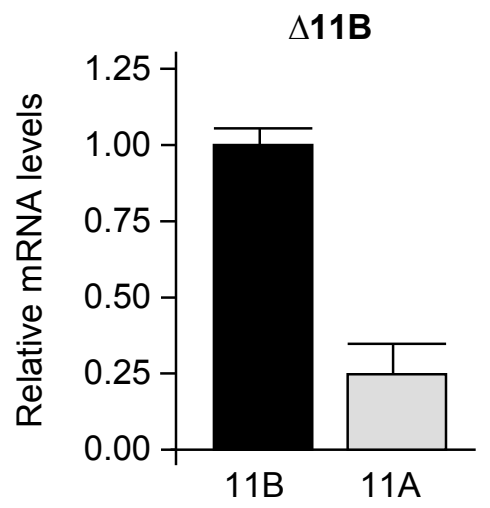

